\title{
Targeting the Tumor Microenvironment: Focus on Angiogenesis
}

\author{
Fengjuan Fan, Alexander Schimming, Dirk Jaeger, and Klaus Podar \\ Medical Oncology, National Center for Tumor Diseases (NCT), University of Heidelberg and German Cancer Research Center (DKFZ), \\ Im Neuenheimer Feld 460, 69120 Heidelberg, Germany \\ Correspondence should be addressed to Klaus Podar, klaus.podar@med.uni-heidelberg.de
}

Received 1 May 2011; Accepted 23 June 2011

Academic Editor: Kalpna Gupta

Copyright (c) 2012 Fengjuan Fan et al. This is an open access article distributed under the Creative Commons Attribution License, which permits unrestricted use, distribution, and reproduction in any medium, provided the original work is properly cited.

\begin{abstract}
Tumorigenesis is a complex multistep process involving not only genetic and epigenetic changes in the tumor cell but also selective supportive conditions of the deregulated tumor microenvironment. One key compartment of the microenvironment is the vascular niche. The role of angiogenesis in solid tumors but also in hematologic malignancies is now well established. Research on angiogenesis in general, and vascular endothelial growth factor in particular, is a major focus in biomedicine and has led to the clinical approval of several antiangiogenic agents including thalidomide, bevacizumab, sorafenib, sunitinib, pazopanib, temesirolimus, and everolimus. Indeed, antiangiogenic agents have significantly changed treatment strategies in solid tumors (colorectal cancer, renal cell carcinoma, and breast cancer) and multiple myeloma. Here we illustrate important aspects in the interrelationship between tumor cells and the microenvironment leading to tumor progression, with focus on angiogenesis, and summarize derived targeted therapies.
\end{abstract}

\section{Introduction}

Cancer research in both solid and hematologic malignancies until recently predominantly focused on the identification of genetic changes which are intimately associated with the induction and progression of tumors and metastasis [1]. A variety of multistep tumor models with accumulating somatic mutations has been proposed [2], most prominently the multistep colon cancer model of Dr. Vogelstein's group $[3,4]$. In addition to focal genetic lesions (point mutations), chromosomal aberrations (e.g., aneuploidy, translocations, chromosomal deletions) as well as epigenetic alterations (e.g., DNA methylation, histone deacetylation, nucleosome remodeling, and RNA-associated silencing) induce deregulated expression of oncogenes and suppressor genes thereby leading to tumor cell proliferation, transformation and invasion $[5,6]$. Recent studies add yet another facet to the complex multistep model of tumorigenesis by demonstrating that tumor cells carrying genomic and epigenomic abnormalities also trigger changes in their microenvironment. In turn, these changes enable the formation of a selective supportive "tumor microenvironment" $[7,8]$.

The cellular tumor microenvironment that is, the bone marrow microenviroment is composed of nonhematopoietic cells including endothelial cells (ECs); cancer-associated fibroblasts (CAFs); and cells involved in bone homeostasis including chondroblasts, osteoclasts, and osteoblasts; and hematopoietic cells including immune cells (including natural killer cells (NK) cells, tumor-associated macrophages (TAMs), T lymphocytes, monocytes); erythrocytes; megakaryocytes and platelets; stem cells; progenitor and precursor cells; and circulating endothelial precursors (CEPs). The noncellular microenvironment is composed of the extracellular matrix (ECM) proteins including fibronectin, laminin, collagen, osteopontin, proteoglycans, and glycosaminoglycans-and the liquid milieu (cytokines and growth factors, proteases) (Table 1). Tumor cellinduced disruption of the microenvironment homeostasis between the highly organized cellular and extracellular compartments support sustained proliferative signaling, evade growth suppressors, resist cell death, enable replicative immortality, activate invasion and metastasis, reprogram energy metabolism, evade immune destruction, and induce drug resistance and angiogenesis. Based on our enhanced understanding of the functional importance of the tumor microenvironment and tumor angiogenesis, in particular, new molecular targets have been identified. 
TABLE 1: Tumor microenvironment and its compartments.

\begin{tabular}{lll}
\hline \multirow{2}{*}{ Microenvironment } & $\begin{array}{l}\text { Epithelial solid tumors } \\
\text { For example, Breast Cancer }\end{array}$ & $\begin{array}{l}\text { Tumor entities } \\
\text { Hematological tumors } \\
\text { Fxtracellular matrix (ECM) example, multiple myeloma }\end{array}$ \\
\hline & $\begin{array}{l}\text { fibronectin, laminin, collagen, proteoglycans, } \\
\text { thrombospondin, fibrinogen, elastin, fibrin, } \\
\text { tenascin, tetranectin }\end{array}$ & $\begin{array}{l}\text { fibronectin, laminin, collagen, proteoglycans, } \\
\text { glycosaminoglycans }\end{array}$ \\
& $\begin{array}{l}\text { Hematopoietic: TAM, T and B lymphocytes, } \\
\text { neutrophils, NK cells, mesenchymal stem cells }\end{array}$ & $\begin{array}{l}\text { Hematopoietic: HSCs, BM-derived CEPs, } \\
\text { hematopoietic and mesenchymal progenitor } \\
\text { and precursor cells, NK cells, NKT cells, } \\
\text { macrophages, T and B lymphocytes, DCs, } \\
\text { monocytes, platelets, megakaryocytes, } \\
\text { erythrocytes } \\
\text { nonhematopoietic: fibroblasts/BMSCs, } \\
\text { chondrocytes, OCs, OBs, ECs }\end{array}$ \\
\hline
\end{tabular}

Hormones: estrogen, progesterone

Liquid

cytokines and growth factors: VEGF, HGF/SF, bFGF, PDGF $\alpha / \beta$, TGF $\alpha / \beta$, IL- 1 , IL- 6 , TNF $\alpha$, GM-CSF, CSF-1, IGF-1/2, EGF, SDF-1

proteases: cathepsin B and D, elastase, uPA, plasmin, MMPs (e.g., MMP-1, -2, -3, -9)
Cytokines and growth factors: VEGF, IGFs, TNF $\alpha$, CD40, IL-1, IL-6, IL-10, IL-11, IL-15, IL-21, HGF, bFGF, SDF-1, TGF $\beta$, LIF, OSM, MIP- $1 \alpha$, Wnts

proteases: uPA, plasmin, MMPs (e.g., MMP-2, -9)

TAM: tumor-associated macrophage; NK: nature killer; CAFS: cancer-associated fibroblasts; EC: endothelial cell; HSC: hematopoietic stem cells; CEP: circulating endothelial precursor; NKT: nature killer T; DC: dendritic cell; BMSC: bone marrow stromal cell; OC: osteoclast; OB: osteoblast; VEGF: vascular endothelial growth factor; HGF/SF: hepatocyte growth factor/scatter factor; bFGF: basic Fibroblast Growth Factors; PDGF: platelet-derived growth factor; TGF: transforming growth factor; TNF: tumor necrosis factor; IL: interleukin; GM-CSF: granulocyte macrophage colony stimulating factor; CSF: colony stimulating factor; EGF: epidermal growth factor; SDF: stromal cell-derived factor; uPA: urokinase plasminogen activator; MMP: matrix metalloproteinase; IGF: Insulin-like growth factor; LIF: leukaemia inhibitory factor; OSM: oncostatin M; MIP-1 $\alpha$ : macrophage inflammatory protein $1 \alpha$.

References for breast cancer: [8-11].

References for multiple myeloma: [12].

This paper aims to illustrate important aspects in the interrelationship between tumor cells and the tumor microenvironment, tumor angiogenesis in particular, in tumor progression. Four tumor entities, in which antiangiogenic agents have already significantly changed treatment strategies, are taken as examples: colorectal cancer (CRC), renal cell carcinoma (RCC), and breast cancer (BC), as well as multiple myeloma (MM).

\section{Tumor Angiogenesis}

Research on tumor angiogenesis is a major focus in biomedicine. Historically, Dr. Virchow was the first to identify a huge number of blood vessels in tumors in 1863 [13]. Few decades later in 1907, Goldman was the first to describe tumor vascularization in carcinomas of the stomach, the liver, and other organs [14]. In 1913, Murphy reported about the angiogenic response induced by Jensen rat sarcoma cells in the chick chorioallantoic membrane (CAM) [15]. The term "angiogenesis" was first used in 1935 and described the formation of new blood vessels in the placenta [16] and four years later in wound healing and tumor growth [17]. However, it was not until 1971 when Folkman hypothesized that inhibition of angiogenesis may be a potential way to inhibit cancer progression [18]. Subsequently, independent studies by Senger and Dvorak, Ferrara and Henzel, as well as Connolly and colleagues led to the purification, identification and cloning of vascular endothelial growth factor (VEGF), the key proangiogenic factor [19-23]. Since then, our knowledge of molecular mechanisms to tumor angiogenesis continually increased leading to the discovery of promising antiangiogenic therapies for tumor patients [24, 25]. Specifically, the impact of the tumor microenvironment, and tumor angiogenesis in particular, has been studied in greater detail in three types of solid cancer (CRC, RCC, $\mathrm{BC}$ - and MM. These diseases serve as paradigm diseases for ongoing studies also in other tumor entities.

During tumorigenesis, the appropriate balance between proangiogenic and antiangiogenic molecules which arise from cancer cells and stromal cells in response to direct cellcell, cell-ECM binding as well as to autocrine and paracrine growth factor stimulation, is lost [26, 27]. The "angiogenic switch", a rapid increase of blood vessel formation to support tumor growth, is triggered by (1) oncogene-mediated tumor expression of angiogenic proteins including VEGF, fibroblast growth factor (FGF), platelet derived growth factor (PDGF), endothelial growth factor (EGF), lysophosphatic acid (LPA), and angiopoietin (Ang), (2) metabolic and/or mechanical stress, (3) genetic mutations, (4) the immune response, and maybe most prominently (5) hypoxia. Tumor-angiogenesis therefore depends on tumor type, site, growth, and stage of disease and contributes to tumor growth, invasion, and metastasis. 
The main mechanism of tumor angiogenesis is endothelial sprouting which crucially depends on VEGF upregulation and the interaction between ECs, pericytes, stroma cells as well as their association with the ECM $[28,29]$. Specifically, VEGF and angiopoietin activate matrix degrading enzymes including the plasminogen activator (PA) and matrix metalloproteinases (MMPs) to loosen the matrix and favor EC migration [30]. VEGF and angiopoietin-2 (Ang2)/type I tyrosine kinase receptor 2 (TIE 2) system then induce the detachment of pericytes and thereby increase vessel porosity. Plasma proteins are exuded and provide a gradient for EC migration [31-34]. Mechanistically, vessel sprouting is mediated by specialized ECs: tip cells lead the new sprout; stalk cells trail behind the pioneering tip cell, proliferate to form an elongating, stalk and create a lumen; and endothelial nonproliferating phalanx cells sense and regulate perfusion in the persistent sprout. Functionally, VEGF induces both NOTCH 1-mediated proliferation in stalk cells as well as directed migration of delta-like 4 (DLL 4)-expressing tip cells towards the sources of angiogenic factors. Endothelial cell-derived factor epidermal growth factor-like domain multiple 7 (Egfl 7) and components of the ECM then regulate vascular lumen formation [35]. Finally, PDGF produced by ECs then recruits pericytes, which surround and stabilize new vessels.

Besides sprouting, the formation of the endothelial lining of tumor vessels is promoted by cooption of neighboring preexisting vessels [36], intussusception (insertion of connective tissue columns into vessel lumen), glomeruloid angiogenesis, as well as VEGF-induced recruitment of highly proliferative circulating endothelial cells (CECs) and endothelial progenitor cells (EPCs) from the BM, hematopoietic stem cells (HSCs), progenitor cells, monocytes, and macrophages [37]. In addition, tumor cells themselves act as ECs to form functional avascular blood conduits or mosaic blood vessels [38-42].

Oxygen tension is the key regulator of VEGF expression, predominantly via the hypoxia-inducible factor (HIF)/von Hippel-Lindau tumor suppressor gene (VHL) pathway. Under normoxic conditions, prolyl hydroxylase domain (PHD) proteins hydroxylate prolyl residues on HIF, which are recognized by VHL, polyubiquitinated, and undergo proteasomal degradation. Tumor growth is often accompanied by a decrease in oxygen tension due to insufficient vascularization [43]. In turn, the process of tumor angiogenesis gets initiated and blood vessels supply nutrients and oxygen for the tumors that reach a hypoxic and necrotic area [43]. Under hypoxic conditions, PHD proteins are inactive, and nonhydroxylated HIF accumulates, translocates to the nucleus and binds to hypoxia-response elements (HRE) thereby initiating transcription of various genes that play a central part in angiogenesis. Genes induced by HIF include VEGF, PDGF, transforming growth factor- $\beta$ (TGF$\beta$ ), TGF $\alpha$, epidermal growth factor receptor (EGFR), insulinlike growth factor 2 (IGF2), MMP1, stromal cell-derived factor 1 (SDF1), glucose transporter 1 (involved in glucose metabolism), as well as carbonic anhydrase 9 (CAIX), and activin B [44-47]. Factor inhibiting HIF (FIH) modulates interaction of HIF with the coactivators CBP/p300 [48].
HIF is also regulated by oxygen-independent pathways via growth-factor receptors or other signaling molecules. Specifically, growth factors, signaling molecules, and loss of function mutations of molecules such as VHL, p53, and PTEN, trigger HIF- $1 \alpha$ synthesis. HIF expression is also controlled by specific microRNAs. A recent study identified a unique microRNA in hypoxic endothelia cells, miR424, that promotes HIF-1 stabilization and angiogenesis $[49,50]$. Importantly, besides being a key regulator of angiogenesis, HIF activity is required for tumor cell survival and proliferation, migration, invasion, $\mathrm{pH}$ regulation, metabolism, drug and radiation resistance, immune evasion, and genetic stability [51,52].

\section{Colorectal Cancer}

Major improvements in the therapy of CRC have been made during the last decades. These improvements are based on our increased knowledge of the role of the tumor microenvironment, and angiogenesis in particular, in CRC tumorigenesis. In the late 1980s, Dr. Vogelstein postulated a paradigm of multistep carcinogenesis in CRC involving a progressive series of specific and well-defined genetic alterations in tumor suppressor genes (APC, p53, or DCC) and in oncogenes (K-Ras), which render normal mucosa to carcinoma $[53,54]$. Besides inducing tumor cell proliferation, survival, migration, and drug resistance, these alterations trigger changes in the tumor microenvironment, tumor angiogenesis in particular, via upregulation of VEGF as well as deregulation of other molecules including EGFR and COX2. Increased levels of VEGF and EGFR expression have been found in patients with localized as well as metastatic CRC [55-60]. Based on successful clinical phase III trials both VEGF inhibitors (e.g., bevacizumab) as well as EGFR inhibitors (e.g., cetuximab, panitumumab) have been approved and incorporated into novel treatment regimens of progressed CRC.

Metabolic products of cyclooxygenase 2 (COX2), prostaglandins in particular, contribute to neovascularisation and support vasculature-dependent growth of CRC, invasion, and metastasis $[31,61,62]$. COX2 is upregulated in approximately $50 \%$ of adenomas and $85 \%$ of adenocarcinomas $[63,64]$ and associated with worse survival among CRC patients [65]. Genetic deletion of COX2 dramatically reduces intestinal polyp formation supporting a key function of COX2 in CRC tumorigenesis [66]. Functionally, COX2 triggers secretion of MMP2 and MMP9 and enhances the expression of proangiogenic growth factors including VEGF and bFGF. It therefore contributes to the dissolution of the collagen matrix, EC migration, and formation of tubular networks [67-70]. COX2 inhibitors suppress VEGF and bFGF expression and thereby block angiogenesis [71-73]. Indeed, both aspirin and nonaspirin-NSAIDs given daily reduce the incidence of CRC significantly $[74,75]$.

Another potential therapeutic target is endoglin, a membrane-steady TGF $\beta$ coreceptor regulating tumorangiogenesis in CRC $[76,77]$. High levels of soluble Endoglin have been found in CRC and $\mathrm{BC}$ patients [78] where it contributes to EC dysfunction $[79,80]$. However, exact mechanism 
of soluble endoglin on tumor angiogenesis remain to be identified.

In summary, inhibitors of growth factors contributing to tumor angiogenesis such as VEGF, EGF, and also COX2 have already been incorporated into novel treatment regimens and maintenance therapies in CRC. Promising future therapeutic targets include endoglin.

\section{Renal Cell Carcinoma}

Renal cell carcinoma/hypernephrom accounts for 2-3\% of all cancer cases in adults. It is the seventh most common cancer in men and the ninth most common in women [81]. While localized RCC has a 5-year survival rate of $60-70 \%$, metastatic RCC is the most lethal of all urological cancers [82]. Resistant to chemotherapy [81], only immunotherapy with IL-2 and interferon $\alpha$ (IFN $\alpha$ ) has been utilized for systemic RCC therapy until most recently [83]. The introduction of antiangiogenic agents has dramatically improved treatment options in metastatic RCC. Indeed, an unprecedented six antiangiogenic agents have been approved for RCC treatment during the last 5 years including sunitinib, temsirolimus, everolimus, pazopanib, bevacizumab, and sorafenib. These agents improve progression-free survival. However, improvements of overall survival have not been demonstrated yet.

The evaluation of antiangiogenic agents for treatment of RCC has been triggered by the finding that RCC is a highly vascular tumor and that increased microvessel density (MVD) correlates with increased risk of metastasis, recurrence and adverse prognosis. High expression of VEGF and other angiogenic factors are predominantly triggered by the inactivation of the VHL tumor suppressor gene due to the loss of $3 p$ [84-88]. Consequently, HIF is not degraded even under normoxic conditions [85]. Furthermore, VHL has many functions that are independent of HIF [89]. For example, inactivated VHL cannot interact with fibronectin and hydroxylated collagen IV. It thereby leads to impaired ECM organization invasion and angiogenesis in RCC [90, 91].

Besides VHL/HIF signaling, other signaling pathways may also participate in the regulation of secreted angiogenic factors in RCC. For example, in VHL-defective RCC cells, oncoprotein HDM2 not only affects constitutively expressed HIF $\alpha$, but also directly regulates protein levels of HIF angiogenic targets (e.g., VEGF, PA inhibitor-1 (PAI-1), and endothelin-1 (ET-1)) [92].

RCC is one of the most immunogenic tumors [93]. Importantly, besides its effects on angiogenesis VEGF modulates immune tolerance in the tumor microenvironment by attenuating dendritic cell differentiation [94], and increasing secretion of immunosuppressive cytokines [95]. Anti-RCC activity of VEGF-inhibitors may therefore, at least in part, also be mediated via modulation of the antitumor immunity.

\section{Breast Cancer}

In 2010, BC was the cancer with the most new cases (207,090 women) of females in the USA and forth highest death rate (39,840 women) [96]. As in CRC and RCC, VEGF expression is also upregulated in BC. Moreover, angiogenesis represents a major independent prognostic factor in BC [97]. VEGF production and secretion within the $\mathrm{BC}$ microenvironment is triggered by a number of stimuli including growth factors, cytokines, hormones, loss of p53 function, RAS and SRC mutations, hypoxia as well as overexpression of HER2 (HER2/neu, ErbB2) [98-100]. Moreover, high levels of MMP- 9 are produced and secreted by $\mathrm{BC}$ cells [101] and release sequestered VEGF from the adjacent ECM [102]. Importantly, VEGF levels are higher in premenopausal patients than in postmenopausal patients indicating that steroid hormones increase VEGF expression [103]. Indeed, upregulation of VEGF in tumor cell lines is triggered by the interaction of the ER $\alpha$ /estradiol-complex with an imperfect estrogen response element located $1.5 \mathrm{~kb}$ upstream of the VEGF transcription start site [104, 105].

HER2 is a member of the EGFR family encoded by the ERB2 gene. In human BC, the HER2 gene is amplified in 20$30 \%$ of all BC $[106,107]$. Phosphorylation of the tyrosine kinase domain results in tumor cell and EC proliferation and survival via PI3K- and Ras/MEK/MAPK-signaling pathways $[57,108,109]$. In addition to phosphorylation, cleavage of the extracellular domain of HER2 generates an intracellular domain (p95) which activates these signaling pathways.

Another regulator of angiogenesis in BC is osteoprotegerin (OPG), a glycoprotein belonging to the TNF receptor (TNFR) superfamily whose production is triggered by direct cell-EC contact [110]. High levels of OPG are present in tumor ECs and correlate with tumor grade in BC [111].

Similarly, the transcription factor HOXB9 is overexpressed in $42 \%$ of patients with BC. It induces production of TGF- $\beta$, ErbB ligands, and several angiogenic factors (VEGF, bFGF, IL-8, and ANGPTL-2) thereby resulting in the induction of mesenchymal cell fate, invasion, as well as angiogenesis [112].

Finally, fes proto-oncogene (also known as $f p s$ ) which encodes a Src homology 2 (SH2) domain-containing cytoplasmic PTK mediates tumor angiogenesis and metastasis [113]. Indeed the tumor microenvironment in Fes-deficient mice showed reduced vascularity and fewer tumor-associated macrophages indicating a therapeutic role for fes-inhibition [114].

In addition to bevacizumab, a variety of additional antiangiogenic agents is under clinical investigation for treatment of $\mathrm{BC}$ in the palliative as well as in the adjuvant setting. Importantly, also the anti-BC activity of tamoxifen is, at least in part, due to its antiangiogenic effect [115-117].

\section{Multiple Myeloma}

MM is a B-cell neoplasm characterized by excess clonal proliferation of malignant plasma cells in the bone marrow, elevated serum and urine monoclonal protein, osteolytic bone lesions, renal disease, and immunodeficiency. MM is the second most frequent malignancy of the blood in the USA. It causes about $1 \%$ of neoplastic diseases and 13\% of hematological malignancies [118, 119]. The development of MM involves both early and late genetic changes in the 
tumor cell as well as selective supportive conditions by the bone marrow (BM) microenvironment, BM angiogenesis in particular [120]. It is suggested that MGUS and nonactive MM in which the tumor growth is arrested are "avascular phases" of plasma cell tumors, while the active MM is the "vascular phase", which is associated with clonal expansion and epigenetic modifications of the microenvironment as well as the "angiogenic switch" [121, 122]. Importantly, these findings correlate with disease progression and poor prognosis. Moreover, BM MVD at the time of initial diagnosis is an important prognostic factor for median overall survival (OS) and median progression-free survival (PFS) in patients undergoing autologous transplantation as frontline therapy for MM [123].

VEGF within the MM BM microenvironment induces growth, survival as well as migration of MM cells in an autocrine manner via VEGFR-1 and triggers angiogenesis via VEGF-2 in ECs [122-127]. Recent studies suggest the existence of MM-specific ECs (MMECs) which produce growth and invasive factors for plasma cells, including VEGF, FGF-2, MMP-2 as well as MMP-9. Compared to healthy human umbilical vein EC (HUVEC), MMECs secrete higher amounts of the CXC chemokines (e.g., IL8, SDF1- $\alpha$, MCP$1)$, which act in a paracrine manner to mediate plasma cell proliferation and chemotaxis [120-123, 126, 128, 129]. In turn, MM cells and stromal cells prolong survival of ECs both by increased secretion of EC survival factors, such as VEGF, and by decreased secretion of antiangiogenic factors $[123,130,131]$.

Based on the enhanced understanding of the functional importance of the MM BM microenvironment and its interrelation with the MM cell resulting in homing, seeding, proliferation and survival, new molecular targets have been identified and derived treatment regimens in MM have already changed fundamentally during recent years. The anti-MM activity of thalidomide, bortezomib, and lenalidomide is mediated, at least in part, also via antiangiogenic effects [132]. For the treatment of MM, additional antiangiogenic therapies are therefore being evaluated in combination with conventional or novel anti-MM therapies $[12,127]$.

\section{Inhibitors of Angiogenesis (Table 2)}

7.1. Thalidomide and the IMiDs (Lenalidomide/Revlimid, Pomalidomide/Actimid). In 1994, D'Amato et al. studied the mechanism of thalidomide's teratogenicity and found that thalidomide (Celgene) is a potential inhibitor of angiogenesis [133]. Based on this finding and the discovery that bone marrow MVD plays a key role in MM pathogenesis, thalidomide was used empirically to treat patients with refractory relapsed MM in the late 90s. Remarkable clinical responses rendered thalidomide to be the first antiangiogenic agent for cancer treatment [134]. Currently, thalidomide is not only used in patients with refractory/relapsed but also with newly diagnosed MM.

Subsequently, a series of thalidomide-derived immunomodulatory drugs (IMiDs) including lenalidomide (Revlimid) and pomalidomide (Actimid) have been developed [135]. A phase I dose-escalation trial using lenalidomide in patients with relapsed and refractory MM demonstrated either response or stabilization of disease in $79 \%$ cases [136]. Two clinical phase II trials confirmed these data and achieved complete responses with favorable side effect profiles; two clinical phase III trials comparing lenalidomide to dexamethasone/lenalidomide treatment of relapsed MM provided the basic for its FDA approval in 2006. In the relapsed/refractory setting an overall response of $30 \%$ was achieved by the new IMID pomalidomide, alone or in combination with dexamethasone. More than 100 clinical studies with thalidomide or lenalidomide combined with other agents are currently recruiting or ongoing.

Adverse side effects of thalidomide and the IMiDs include polyneuropathy, fatigue, skin rash, and venous thromboembolism (VTE), or blood clots, which could lead to stroke or myocardial infarction. Both thalidomide and the IMiDs overcome the growth and survival advantage conferred by the BM milieu, at least in part by downregulating VEGF [137, 138], and inhibition of proliferation and capillarogenesis of MMECs [128].

7.2. Bevacizumab (Avastin). Bevacizumab (Genetech) [139] binds biologically active forms of VEGF and prevents its interaction with VEGF receptors (VEGFR-1 and VEGFR2 ), thereby inhibiting endothelial cell proliferation and angiogenesis. In preclinical studies bevacizumab reduced microvascular growth and inhibited metastasis of colon growth in nude mice [140-142].

When tested in patients with metastatic CRC bevacizumab in combination with conventional chemotherapy demonstrated significant survival benefits. Based on this finding, the US FDA approved bevacizumab in February 2004, followed by the EMEA approval in January 2005, as first-line treatment of metastatic CRC in combination with 5-fluorouracil-(FU-) based chemotherapy regimens. In 2006, bevacizumab in combination with 5-FU was also approved for second-line treatment of CRC. In contrast, the use of bevacizumab in the adjuvant setting cannot be recommended [143-145]. Bevacizumab is therefore the first VEGF-targeting agent approved both by the US FDA as well as the EMEA for cancer treatment [146].

Since its initial approval as first-line treatment in metastatic CRC in 2004, bevacizumab has been approved for use in combination with other chemotherapeutics in four other tumor types: in 2009 (US) and 2007 (EU) for advanced RCC, in 2008 for metastatic HER2-negative BC, in 2009 for glioblastoma, and in 2004 for non-small cell lung cancer (NSCLC) [147-150].

Specifically, the E2100 study was the first Phase III study using bevacizumab in metastatic $\mathrm{BC}$ as first-line treatment. Bevacizumab was investigated in combination with and without paclitaxel. In combination with bevacizumab, progression-free survival was doubled (5.8 months to 11.3 months). The overall response rate increased from 22 to $50 \%$. Because of this study, bevacizumab was approved for metastatic BC [151]. But as the overall survival did not show any benefit, Fojo and Wilkerson [152] believe that the E2100 trial overestimated the benefit of bevacizumab and 
TABLE 2: Summary of drugs, their revealed targets and indications in clinical trails. Drugs without a single treatment trial are marked with a “*”.

\begin{tabular}{|c|c|c|c|c|}
\hline $\begin{array}{l}\text { Drug (brand name, } \\
\text { company) }\end{array}$ & Target & Approved & $\begin{array}{l}\text { Clinical trials with } \\
\text { single treatment }\end{array}$ & Indication \\
\hline $\begin{array}{l}\text { Bevacizumab (Avastin, } \\
\text { Genentech/Roche) }\end{array}$ & $\begin{array}{l}\text { Monoclonal antibody } \\
\text { against VEGFA }\end{array}$ & $\begin{array}{l}\text { mCRC, mRCC, NSCLC, } \\
\text { metastatic HER2-negative } \\
\text { breast cancer, } \\
\text { glioblastoma }\end{array}$ & Phase I, II & $\begin{array}{l}\text { Multiple solid tumors (e.g., RCC, } \\
\text { BC, pancreatic, prostate, ovarian, } \\
\text { brain cancers) and hematologic } \\
\text { malignancies (e.g., MM) }\end{array}$ \\
\hline $\begin{array}{l}\text { Sunitinib, SU11248 } \\
\text { (Sutent, Pfizer) }\end{array}$ & $\begin{array}{l}\text { TKI of VEGFR } 1-3 \text {, } \\
\text { PDGFR } \alpha / \beta, c-K i t, \text { Flt } 3 \text {, } \\
\text { RET, CSF-1R }\end{array}$ & mRCC, GIST & Phase I & $\begin{array}{l}\text { Multiple solid tumors (e.g., RCC, } \\
\text { BC, melanoma, lung) }\end{array}$ \\
\hline $\begin{array}{l}\text { Pazopanib (Votrient, } \\
\text { GlaxoSmithKline) }\end{array}$ & $\begin{array}{l}\text { TKI of VEGFR 1-3, } \\
\text { PDGFR } \alpha / \beta, \text { c-kit } \\
\text { tyrosine kinases }\end{array}$ & mRCC & Phase I, II & $\begin{array}{l}\text { Multiple solid tumors (e.g., BC, } \\
\text { RCC, ovarian, lung) and others } \\
\text { (e.g., lymphoma) }\end{array}$ \\
\hline
\end{tabular}

TKI of Multiple cell surface kinases (VEGFR $1-3$, RET, PDGFR $\beta$,

Sorafenib, BAY43-9006

(Nexavar, Bayer) Flt-3, c-Kit, CSF-1) and intracellular kinases (CRAF, BRAF, mutant BRAF)

Vandetanib, ZD6474 (Zactima, AstraZeneca)

Bortezomib, PS-341

(Velcade, Millennium Pharmaceuticals)

TKI of VEGFR, EGFR

Metastatic medullary thyroid cancer

mRCC, unresectable hepatocellular carcinoma

Phase I, II

Multiple solid tumors (e.g., RCC, $\mathrm{BC}$, melanoma, lung cancers) and hematologic malignancies (e.g., MM) and RET 26S proteasome inhibitor

MM, relapsed mantle cell lymphoma

Phase I, II

Temsirolimus (Torisel, Wyeth)

mTOR inhibitor

mRCC

Phase I, II

Everolimus, RAD001

(Afinitor, Novartis)

mTOR inhibitor

Advanced renal cell carcinoma

Phase I, II

Thalidomide (Thalomid, Angiogenesis inhibitor, Celgene) multiple

MM

$*$

MM

Lenalidomide, CC-5013 Angiogenesis inhibitor, (Revlimid, Celgene) Thalidomide derivative

MM Phase I, II

Pomalidomide, CC-4047 Angiogenesis inhibitor, (Actimid, Celgene) Thalidomide derivative

Aflibercept, VEGF-trap

(ZALTRAP,

Sanofi-Aventis and

Decoy receptor for all

Regeneron)

Axitinib, AG-013736

(Pfizer)

VEGF-A isoforms

No yet approved

No yet approved

Phase I

MM, lymphoma, chronic lymphocytic leukemia, and multiple solid tumors (e.g., CRC, ovarian) C, lung, prostate

Multiple solid tumors (e.g., RCC, $\mathrm{BC}$, melanoma, prostate, liver cancers) and hematologic malignancies (e.g., lymphoma)

Multiple solid tumors (e.g., BC, pancreatic, gastric cancers) and lymphoma

MM

\begin{tabular}{|c|c|c|c|c|}
\hline & CSF-1 & & & cancer, thyroid cancer \\
\hline $\begin{array}{l}\text { Icrucumab, IMC-18F1 } \\
\text { (ImClone) }\end{array}$ & $\begin{array}{l}\text { Monoclonal antibody } \\
\text { against VEGFR-1 }\end{array}$ & No yet approved & Phase I & $\begin{array}{l}\text { Advanced solid tumors, (e.g., } \\
\text { CRC, BC, carcinoma of urinary } \\
\text { tract) }\end{array}$ \\
\hline $\begin{array}{l}\text { Ramucirumab, } \\
\text { IMC-1121b (ImClone) }\end{array}$ & $\begin{array}{l}\text { Monoclonal antibody } \\
\text { against VEGFR-2 }\end{array}$ & No yet approved & $*$ & $\begin{array}{l}\text { CRC, BC, mRCC, Advanced } \\
\text { liver, gastric, prostate, ovarian, } \\
\text { and NSCL cancers, melanoma }\end{array}$ \\
\hline $\begin{array}{l}\text { Vatalanib, PTK787 } \\
\text { (Novartis) }\end{array}$ & $\begin{array}{l}\text { TKI of VEGFR } 1-3 \text {, } \\
\text { PDGFR } \alpha / \beta \text {, and c-KIT }\end{array}$ & Not yet approved & $*$ & $\begin{array}{l}\text { Multiple solid tumors (e.g., CRC, } \\
\text { glioblastoma, NSCLCs) and } \\
\text { hematologic malignancies (e.g., } \\
\text { leukemia) }\end{array}$ \\
\hline
\end{tabular}

mCRC, RCC, Ovarian, NSCLC, prostate cancers, lymphoma, leukemia

mRCC, BC, NSCLC, metastatic pancreatic cancer, GIST, lung cancer, thyroid cancer
TKI of VEGFR 1-3, PDGFR $\beta$, c-KIT and No yet approved Phase I 
TABle 2: Continued.

\begin{tabular}{|c|c|c|c|c|}
\hline $\begin{array}{l}\text { Drug (brand name, } \\
\text { company) }\end{array}$ & Target & Approved & $\begin{array}{l}\text { Clinical trials with } \\
\text { single treatment }\end{array}$ & Indication \\
\hline $\begin{array}{l}\text { Enzastaurin, } \\
\text { LY317615.HCl (Eli Lilly) }\end{array}$ & PKC inhibitor & Not yet approved & * & $\begin{array}{l}\text { BC, mCRC, Brain tumor, } \\
\text { advanced NSCL, glioblastoma, } \\
\text { lymphoma }\end{array}$ \\
\hline $\begin{array}{l}\text { Cediranib, AZD2171 } \\
\text { (Recentin, AstraZeneca) }\end{array}$ & TKI of VEGFR 1-3 & Not yet approved & Phase I & $\begin{array}{l}\text { RCC, CRC, BC, ovarian, prostate } \\
\text { cancer, lung, brain, head and } \\
\text { neck cancers, glioblastoma, } \\
\text { melanoma }\end{array}$ \\
\hline $\begin{array}{l}\text { Vectibix, panitumumab } \\
\text { (Amgen) }\end{array}$ & EGFR & mCRC & Phase I, II & $\begin{array}{l}\text { mCRC, pancreatic, HNSCC, } \\
\text { NSCLC, lung }\end{array}$ \\
\hline $\begin{array}{l}\text { Erbitux, cetuximab, } \\
\text { (Imclone, Bristol-Myers } \\
\text { Squibb) }\end{array}$ & EGFR & mCRC & Phase I, II & $\begin{array}{l}\text { mCRC, HSNCC, brain, MM, } \\
\text { lung, pancreatic, liver }\end{array}$ \\
\hline $\begin{array}{l}\text { Trastuzumab, herceptin } \\
\text { (Genentech) }\end{array}$ & HER2 receptor & $\begin{array}{l}\text { Gastric cancer, HER2 } \\
\text { positive BC }\end{array}$ & Phase I, II & $\mathrm{BC}$, gastric \\
\hline $\begin{array}{l}\text { Tykerb, lapatinib } \\
\text { (GlaxoSmithKline) }\end{array}$ & $\begin{array}{l}\text { EGFR and HER2 } \\
\text { receptor }\end{array}$ & $\mathrm{BC}$ & Phase I, II & $\begin{array}{l}\text { BC, CRC, lung, HNSCC, } \\
\text { pancreatic, melanoma }\end{array}$ \\
\hline $\begin{array}{l}\text { Tamoxifen, Novadex, } \\
\text { Istubal, Valodex } \\
\text { (AstraZeneca) }\end{array}$ & Estrogen receptor & $\mathrm{BC}$ & Phase I, II & BC, bladder, melanoma, prostate \\
\hline
\end{tabular}

TKI: tyrosine kinase inhibitors; mCRC: metastatic colorectal cancer; NSCLC: nonsmall cell lung cancer; mRCC: metastatic renal cell carcinoma; GIST: gastrointestinal stroma tumor after progression; MM: multiple myeloma; BC: breast cancer; HNSCC: head and neck sequmous cell carcinoma.

that further studies need to target the VEGF polymorphism of VEGF in order to identify the patients that derive true benefit from bevacizumab [153]. Based on two double-blind studies (AVADO and RIBBON-1) showing high toxicity without significant improvements of progression-free survival [154-156], the use of bevacizumab as first-line therapy in progressed Her2-negative $\mathrm{BC}$ has been removed by the US FDA in 2010. In a meta-analysis, Ranpura et al. report that addition of bevacizumab to systemic antineoplastic therapy is associated with a significantly increased risk (relative risk of 1.46; incidence, $2.5 \%$ versus 1.7\%) of fatal adverse events (FAEs), in BC patients [157, 158]. However, clinical studies evaluating bevacizumab in combination with conventional therapies both in Her2-negative and also Her2positive patients are ongoing. It may be possible to focus bevacizumab treatment in patients most likely to benefit, and avoid treatment of patients unlikely to benefit or more likely to experience toxic effects [157].

Although generally well tolerated, side effects of bevacizumab treatment include minor (hypertension, proteinuria, nosebleed, upper respiratory infection, gastrointestinal symptoms, and headache) and rarely serious (gastrointestinal perforations, hemorrhage, and thrombolysis) adverse effects.

7.3. Cetuximab (Erbitux). Cetuximab (Merck, ImClone, Briston-Myers-Squibb) is a recombinant, human-IgG1/ mouse chimeric monoclonal antibody which blocks phosphorylation and activation of receptor-associated kinases by binding to the receptor. Erbitux is single-used or used in combination with other therapies to treat CRC. The US FDA used three separate clinical trials as a base to approve Erbitux for treatment of EGFR-expressing, recurrent metastatic CRC in patients who are intolerant to irinotecan-based chemotherapy in 2004. In 2007, the US FDA expanded labeling and granted regular approval for single-agent cetuximab for the treatment of patients with EGFR-expressing metastatic CRC after failure of both irinotecan- and oxaliplatin-based chemotherapy regimens (http://www.cancer.gov/).

Known side-effects are rash, asthenia/malaise, diarrhea, nausea, abdominal pain, vomiting, fever, and infusion reaction [159-162].

7.4. Panitumumab (Vectibix). Panitumumab (Amgen), a recombinant, human IgG2 kappa monoclonal antibody, binds specifically to the extracellular domain of EGFR and thereby prevents its activation and downstream signaling sequeale [163-166]. In 2006, panitumumab was approved by the US FDA for treatment of EGFR-expressing metastatic CRC with disease progression despite prior treatment; in 2008 by the EMEA for the treatment of refractory EGFRexpressing metastatic CRC in patients with nonmutated KRas.

Known side-effects include dermatological toxicities, ocular toxicities, hypomagnesemia, fatigue, abdominal pain, nausea, diarrhea and constipation.

7.5. VEGF-Trap (ZALTRAP, Aflibercept), HuMV833, and Other Monoclonal Antibodies Targeting VEGF. VEGF-trap (Sanofi-Aventis and Regeneron) is a soluble decoy receptor protein consisting of a hybrid Fc construct in which domain 2 of VEGFR-1 is fused to domain 3 of the VEGFR$2[167,168]$. VEGF-trap is known to have high affinity 
to all isoforms of VEGF-A. It caused vessel-regression of coopted vessels in a model of neuroblastoma [169]. Several clinical phase II/III trials testing the VEGF-trap in solid and hematologic malignancies including CRC, MM, pancreatic cancer, prostate cancer, NSCLC are ongoing (http://clinicaltrials.gov/). On April 26, 2011, SanofiAventis and Regeneron reported about the positive phase III results with VEGF-trap in second-line mCRC. The VELOUR study evaluates ZALTRAP in combination with FOLFIRI chemotherapy versus FOLFORI plus placebo. Exact results are eagerly awaited for the second half of 2011.

Similarly, HuMV833, a humanized monoclonal IgG antibody-binding VEGF-A isoforms (VEGF121 and VEGF165), demonstrated antitumor effects in a variety of human tumor xenograft models [170, 171].

Additionally, antibodies against VEGFR-1 or VEGFR2 (IMC-18F1, IMC-1121B, ImClone) are under preclinical and clinical investigation. IMC- $18 \mathrm{~F} 1$ is a fully human, high affinity neutralizing antibody that specifically blocks VEGFR-1 activation, which has demonstrated preclinical activity in BC [172]. IMC-1121B (ramucirumab), a fully human monoclonal IgG1 antibody against the extracellular domain of VEGFR-2, is currently under evaluation in various entities including advanced liver, kidney, prostate, ovarian, colorectal, melanoma, BC, and NSCL cancer $[173,174]$.

7.6. Trastuzumab (Herceptin). Trastuzumab (Genentech) is a recombinant humanized monoclonal antibody which binds to the extracellular domain of the HER2 receptor and inhibits the intracellular tyrosine kinase activity. In addition, it blocks cleavage of HER2 and thereby the production of p95, interferes with either homodimerization or heterodimerization of HER2 with itself or other HER receptors, and recruits Fccompetent immune effector cells and other components of antibody-dependent cell-mediated cell cytotoxicity (ADCC). In 1998, trastuzumab was FDA approved for treatment of patients with HER2-positive metastatic BC in combination with paclitaxel. In 2006, FDA approval of trastuzumab was expanded for the adjuvant setting in combination with chemotherapy regimens containing doxorubicin, cyclophosphamide, and paclitaxel. In January 2008, FDA approval was revised to include the use of trastuzumab also as a single agent in the adjuvant setting [175].

7.7. Small Molecule Inhibitors. Although Avastin is an effective medication and studies testing the VEGF-trap or VEGFR-targeting antibodies are promising, drug resistance always develops likely due to targeting a single tumorigenic pathway. Indeed extended blockade of VEGF alone results in tumor revascularization, dependent on other proangiogenic factors such as FGF [176]. Small-molecule inhibitors have the advantage of being orally available as well as more promiscuous in target inhibition and also less expensive $[177,178]$. Based on these therapeutic advantages, many tyrosine kinase inhibitors (TKIs) have been developed and subjected to clinical trials. Indeed, the second-generation multi-targeted receptor kinase inhibitors (RTKIs) sorafenib, sunitinib, and pazopanib have now been approved for the treatment of advanced RCC and gastrointestinal stroma tumor (GIST), hepatocellular carcinoma (HCC). Moreover, preliminary data in other malignancies, most prominently including $\mathrm{CRC}$ and $\mathrm{BC}$ are promising.

7.7.1. Sorafenib (Nexavar). Sorafenib (Bayer HealthCare Pharmaceuticals and Onyx Pharmaceuticals) $[179,180]$ is a RTK inhibitor which targets VEGFR2, VEGFR-3, Raf, $\operatorname{PDGFR} \beta$, Flt3, and c-Kit. It was approved for the treatment of advanced RCC in 2005 and for the treatment of unresectable HCC in 2007. Advanced clinical studies in NSCLC and melanoma are ongoing.

7.7.2. Sunitinib (Sutent). Sunitinib (Pfizer) is another multitargeted TKI which targets VEGFR2, PDGFR $\alpha / \beta$, c-Kit, Flt3, RET [181-184]. Based on a phase III clinical trial, in which sunitinib demonstrated improvements in progression-free survival when compared to IFN $\alpha$, it was approved for firstline and second-line therapy of metastatic RCC $[185,186]$. In addition, sunitinib was also approved for treatment of GIST in 2006 [187]. Advanced clinical studies are ongoing in breast, colorectal, and lung cancer. Both sorafenib and sunitinib alone or in combination therapy are under clinical evaluation in MM.

7.7.3. Temsirolimus (Torisel) and Everolimus (Afinitor). Temsirolimus (Wyeth Pharmaceuticals), a derivative of rapamycin, is a specific inhibitor of the mammalian target of rapamycin (mTOR). mTOR pathway has an important role in regulating the synthesis of HIF and proteins that control cell proliferation, such as c-myc and cyclin D1. Therefore, inhibiting mTOR in RCC downregulates HIF activity and stops the production of cell-cycle regulators $[188,189]$. In 2007, Temsirolimus was approved for the treatment of advanced RCC. As compared with IFN $\alpha$, temsirolimus improved overall survival among patients with mRCC and poor prognosis [190].

Everolimus (Novartis), another rapamycin analogue was approved for treatment of patients with mRCC whose disease had progressed despite prior treatment with sunitinib, sorafenib, or both in 2009 [191, 192].

Clinical studies which evaluate the activity of temsirolimus and everolimus in other tumor entities including $\mathrm{BC}$, gastric cancer, HCC, MM, and lymphoma are ongoing.

7.7.4. Pazopanib (Votrient). Pazopanib (GlaxoSmithKline) is a novel orally available, small-molecule tyrosine kinase inhibitor of VEGF-receptor-1, -2, -3 with IC50's of 10, 30, and $47 \mathrm{nM}$, respectively. In 2010, pazopanib was approved as the third TKI and the last among the six treatments for mRCC (sorafenib, sunitinib, temsirolimus, everolimus, bevacizumab) approved by the FDA during the last 5 years. The basis for this approval was a randomized, double-blind, placebo-controlled phase III study evaluating the efficacy and safety of pazopanib in 435 patients with locally advanced and/or mRCC. The median PFS for the pazopanib was 9.2 months compared with 4.2 months for the placebo in overall population $(P<0.001)$ [193]. Moreover, the combination of 
pazopanib with lapatinib was effective in patients with $\mathrm{BC}$, and preclinical data in MM were promising [194]. Clinical studies which evaluate the activity of pazopanib in other tumor entities are ongoing.

7.7.5. Axitinib. Axitinib (Pfizer) is an oral, potent, and selective inhibitor of VEGFR 1-3, PDGFR $\beta$, and c-KIT. Promising data from a clinical phase I study [195] prompted the clinical evaluation of Axitinib in a variety of malignancies. Excitingly, clinical activity has now been demonstrated in sorafenib-refractory metastatic RCC [196] and patients with advanced NSCLC [197]. Moreover, a clinical phase III trial in patients with unresectable, locally advanced, or metastatic pancreatic cancer treated with gemcitabine plus axitinib is now ongoing to verify a small gain in overall survival observed in a clinical phase II trial [198]. Clinical trials in mCRC showed no benefit of axitinib in firstand second-line combination therapies with oxaliplatincontaining chemotherapies in comparison to bevacizumab [199].

Additional clinical studies are ongoing in GIST, lung cancer, thyroid cancer, and breast cancer. Dose-limiting toxicities primarily seen at higher dose levels included hypertension, hemoptysis, and stomatitis. The observed hypertension was manageable with medication. Stomatitis was generally tolerable and managed by dose reduction or drug holidays.

7.7.6. Lapatinib (Tyverb). Lapatinib (GlaxoSmithKline) is another orally available TKI inhibiting both EGFR and HER2 receptors [200-202]. It was FDA approved in 2007 for combination therapy for triple-positive BC patients already treated with capecitabine or which have progressed on trastuzumab. In 2010, lapatinib additionally received accelerated approval as front-line therapy in this patient cohort.

Side effects of Tyverb include diarrhea, palmar-plantar erythrodysesthesia, nausea, rash, vomiting, muscular inflammation, stomatitis, pain in extremities, dyspnea, and fatigue [203-206].

\section{Discussion}

Recent studies delineate a key role for the tumor microenvironment in tumorigenesis. Investigating the complex functional interrelation between the cellular and noncellular compartments of the tumor microenvironment has already led to the identification of new therapeutic targets. One pivotal compartment within the microenvironment is the vascular niche. Indeed, 40 years after Dr. Folkman's seminal postulation in 1971 that angiogenesis is required for tumor growth and progression and may therefore represent a new target for cancer therapy [18], it is well established that angiogenesis plays an important role in solid as well as in hematologic malignancies. Tumor angiogenesis is now recognized to be a hallmark of cancer, initiated by enhanced tumor/tumor-stroma cell-specific production of proangiogenic molecules, and/or suppression of antiangiogenic factors (angiogenic switch) as well as via tumor-associated hypoxia. The introduction of antiangiogenic agents into clinical practice was a milestone event in cancer therapy during the last decade.

VEGF, EGF, and PDGF represent key factors in tumor angiogenesis. Blocking $\mathrm{BM}$ angiogenesis in $\mathrm{MM}$ with thalidomide; and VEGF with the first-in-class antiangiogenic drug bevacizumab; or EGFR with cetuximab in $\mathrm{CRC}$ have become established anticancer strategies. Following the introduction of bevacizumab, efforts focused on the identification of compounds targeting VEGF signaling sequelae that can be given orally. Several second-generation orally available small-molecule antiangiogenic drugs have now been identified including sunitinib, pazopanib, and sorafenib and have recently been approved for treatment of cancers including CRC, BC, RCC, and MM. However the optimal use of antiangiogenics is tumor- and stagedependent. Moreover, although antiangiogenic antibodies as well as small molecules targeting VEGF and EGF signaling pathways significantly prolong overall survival of cancer patients, resistance always develops and disease relapse is inevitable. Recent molecular mechanistic studies may explain the disappointing results of previous clinical studies using VEGF inhibitors alone either in early or refractory/progressive disease. Modest, though significant, survival benefits were observed in patients with advanced tumors treated with bevacizumab and other antiangiogenics even when combined with conventional chemotherapies. Further studies are needed to increase our understanding of tumor angiogenesis and of how resistance against antiangiogenic agents develops. Potential mechanisms of evasive resistance include the redundancy of proangiogenic signals in later disease stages; recruitment of vascular progenitor cells and proangiogenic monocytes from the bone marrow, increased and tight pericyte coverage, or increased capabilities for invasion and metastasis; preexisting inflammatory cell-mediated vascular protection; hypovascularity; invasive and metastatic cooption of normal vessels; and mutational alteration of genes within endothelial cells [207]. Therapeutic benefits may be achieved by initiating treatment with VEGF-inhibitors early: by using antiangiogenic cocktails, which not only target VEGF both in patients with early and late-stage disease, as well as metronomic therapy [208].

Novel approaches to improve antiangiogenic therapy include strategies to target the angiopoietin-TIE system, Hif1, endothelial-specific integrin/survival signaling (e.g., by cilengitide) as well as the use of vascular-disrupting agents (VDAs), which selectively disrupt already existing tumor vessels by targeting dysmorphic endothelial cells. Given the benefits of combination therapy, it is also crucial to optimize existing or identify new treatment regimens in order to reduce drug-associated toxic side effects.

In summary, antiangiogenic compounds like thalidomide, bevacizumab, sorafenib, sunitinib, and pazopanib, temsirolimus and everolimus have already demonstrated activity in a variety of cancers most prominently including BC, CRC, RCC, and MM. However, with the increase of our knowledge of the complexity of molecular mechanisms contributing to tumor angiogenesis in general, and MM $\mathrm{BM}$ angiogenesis in particular, we aim to identify additional 
therapeutic targets, to further optimize treatment regimens; and to reduce mechanisms leading to antiangiogenic drugresistance in order to further improve patient outcome and reduce drug toxicity.

\section{Acknowledgment}

F. Fan and A. Schimming contributed equally to this paper.

\section{References}

[1] M. R. Stratton, "Exploring the genomes of cancer cells: progress and promise," Science, vol. 331, no. 6024, pp. 1553 1558, 2011.

[2] W. C. Hahn and R. A. Weinberg, "Rules for making human tumor cells," The New England Journal of Medicine, vol. 347, no. 20, pp. 1593-1603, 2002.

[3] J. E. Green and T. Hudson, "The promise of genetically engineered mice for cancer prevention studies," Nature Reviews Cancer, vol. 5, no. 3, pp. 184-198, 2005.

[4] B. Vogelstein, E. R. Fearon, S. R. Hamilton et al., "Genetic alterations during colorectal-tumor development," The New England Journal of Medicine, vol. 319, no. 9, pp. 525-532, 1988.

[5] A. S. Perry, R. W. G. Watson, M. Lawler, and D. Hollywood, "The epigenome as a therapeutic target in prostate cancer," Nature Reviews Urology, vol. 7, no. 12, pp. 668-680, 2010.

[6] A. Portela and M. Esteller, "Epigenetic modifications and human disease," Nature Biotechnology, vol. 28, no. 10, pp. 1057-1068, 2010.

[7] D. Hanahan and R. A. Weinberg, "Hallmarks of cancer: the next generation," Cell, vol. 144, no. 5, pp. 646-674, 2011.

[8] M. J. Bissell and W. C. Hines, "Why don't we get more cancer? A proposed role of the microenvironment in restraining cancer progression," Nature Medicine, vol. 17, no. 3, pp. 320329, 2011.

[9] L. Ronnov-Jessen, O. W. Petersen, and M. J. Bissell, "Cellular changes involved in conversion of normal to malignant breast: importance of the stromal reaction," Physiological Reviews, vol. 76, no. 1, pp. 69-125, 1996.

[10] T. Vargo-Gogola and J. M. Rosen, "Modelling breast cancer: one size does not fit all," Nature Reviews Cancer, vol. 7, no. 9, pp. 659-672, 2007.

[11] S. Banerjee, M. Dowsett, A. Ashworth, and L. A. Martin, "Mechanisms of disease: angiogenesis and the management of breast cancer," Nature Clinical Practice Oncology, vol. 4, no. 9, pp. 536-550, 2007.

[12] K. Podar, D. Chauhan, and K. C. Anderson, "Bone marrow microenvironment and the identification of new targets for myeloma therapy," Leukemia, vol. 23, no. 1, pp. 10-24, 2009.

[13] R. Virchow, Ed., Die Krankhaften Geschwülste, Hirschwald, Berlin, Germany, 1863.

[14] E. Goldmann, "The growth of malignant disease in man and the lower animals, with special reference to the vascular system," Proceedings of the Royal Society of Medicine, vol. 1, pp. 1-13, 1908.

[15] J. B. Murphy, "Transplantability of tissues to the embryo of foreign species : its bearing on questions of tissue specificity and tumor immunity," Journal of Experimental Medicine, vol. 17, no. 4, pp. 482-493, 1913.
[16] A. T. Hertig, "Angiogenesis in the early human chorion and in the primary placenta of the macaque monkey," Contributions to Embryology, vol. 25, pp. 37-81, 1935.

[17] A. G. Ide, N. H. Baker, and S. L. Warren, "Vascularization of the Brown Pearce rabbit epithelioma tranplant as seen in the transparent ear chamber," American Journal of Roentgenology, vol. 42, pp. 891-899, 1939.

[18] J. Folkman, "Tumor angiogenesis: therapeutic implications," The New England Journal of Medicine, vol. 285, no. 21, pp. 1182-1186, 1971.

[19] N. Ferrara and W. J. Henzel, "Pituitary follicular cells secrete a novel heparin-binding growth factor specific for vascular endothelial cells," Biochemical and Biophysical Research Communications, vol. 161, no. 2, pp. 851-858, 1989.

[20] N. Ferrara, "Vascular endothelial growth factor," Arteriosclerosis, Thrombosis, and Vascular Biology, vol. 29, no. 6, pp. 789-791, 2009.

[21] D. R. Senger, S. J. Galli, A. M. Dvorak, C. A. Perruzzi, V. Susan Harvey, and H. F. Dvorak, "Tumor cells secrete a vascular permeability factor that promotes accumulation of ascites fluid," Science, vol. 219, no. 4587, pp. 983-985, 1983.

[22] D. W. Leung, G. Cachianes, W. J. Kuang, D. V. Goeddel, and N. Ferrara, "Vascular endothelial growth factor is a secreted angiogenic mitogen," Science, vol. 246, no. 4935, pp. 13061309, 1989.

[23] P. J. Keck, S. D. Hauser, G. Krivi et al., "Vascular permeability factor, an endothelial cell mitogen related to PDGF," Science, vol. 246, no. 4935, pp. 1309-1312, 1989.

[24] D. Hanahan and J. Folkman, "Patterns and emerging mechanisms of the angiogenic switch during tumorigenesis," Cell, vol. 86, no. 3, pp. 353-364, 1996.

[25] L. M. Ellis and D. J. Hicklin, "VEGF-targeted therapy: mechanisms of anti-tumour activity," Nature Reviews Cancer, vol. 8, no. 8, pp. 579-591, 2008.

[26] D. Hanahan and R. A. Weinberg, "The hallmarks of cancer," Cell, vol. 100, no. 1, pp. 57-70, 2000.

[27] M. M. Mueller and N. E. Fusenig, "Friends or foes-bipolar effects of the tumour stroma in cancer," Nature Reviews Cancer, vol. 4, no. 11, pp. 839-849, 2004.

[28] M. S. Gordon, D. S. Mendelson, and G. Kato, "Tumor angiogeiiesis and novel antiangiogenic strategies," International Journal of Cancer, vol. 126, no. 8, pp. 1777-1787, 2010.

[29] A. S. Chung, J. Lee, and N. Ferrara, "Targeting the tumour vasculature: insights from physiological angiogenesis," Nature Reviews Cancer, vol. 10, no. 7, pp. 505-514, 2010.

[30] H. M. Eilken and R. H. Adams, "Dynamics of endothelial cell behavior in sprouting angiogenesis," Current Opinion in Cell Biology, vol. 22, no. 5, pp. 617-625, 2010.

[31] A. R. Nelson, B. Fingleton, M. L. Rothenberg, and L. M. Matrisian, "Matrix metalloproteinases: biologic activity and clinical implications," Journal of Clinical Oncology, vol. 18, no. 5, pp. 1135-1149, 2000.

[32] P. Nangia-Makker, Y. Honjo, R. Sarvis et al., "Galectin-3 induces endothelial cell morphogenesis and angiogenesis," American Journal of Pathology, vol. 156, no. 3, pp. 899-909, 2000.

[33] J. Gamble, G. Meyer, L. Noack et al., "B1 integrin activation inhibits in vitro tube formation: effects on cell migration, vacuole coalescence and lumen formation," Endothelium, vol. 7, no. 1, pp. 23-34, 1999.

[34] S. Yang, J. Graham, J. W. Kahn, E. A. Schwartz, and M. E. Gerritsen, "Functional roles for PECAM-1 (CD31) and VEcadherin (CD144) in tube assembly and lumen formation 
in three-dimensional collagen gels," American Journal of Pathology, vol. 155, no. 3, pp. 887-895, 1999.

[35] L. H. Parker, M. Schmidt, S. W. Jin et al., "The endothelialcell-derived secreted factor Egfl7 regulates vascular tube formation," Nature, vol. 428, no. 6984, pp. 754-758, 2004.

[36] J. Holash, P. C. Maisonpierre, D. Compton et al., "Vessel cooption, regression, and growth in tumors mediated by angiopoietins and VEGF," Science, vol. 284, no. 5422, pp. 1994-1998, 1999.

[37] S. Rafii, D. Lyden, R. Benezra, K. Hattori, and B. Heissig, "Vascular and haematopoietic stem cells: novel targets for anti-angiogenesis therapy?" Nature Reviews Cancer, vol. 2, no. 11, pp. 826-835, 2002.

[38] R. Folberg, M. J. C. Hendrix, and A. J. Maniotis, "Vasculogenic mimicry and tumor angiogenesis," American Journal of Pathology, vol. 156, no. 2, pp. 361-381, 2000.

[39] Y. S. Chang, E. Di Tomaso, D. M. M, R. Jones, R. K. Jain, and L. L. Munn, "Mosaic blood vessels in tumors: frequency of cancer cells in contact with flowing blood," Proceedings of the National Academy of Sciences of the United States of America, vol. 97, no. 26, pp. 14608-14613, 2000.

[40] G. D. Yancopoulos, S. Davis, N. W. Gale, J. S. Rudge, S. J. Wiegand, and J. Holash, "Vascular-specific growth factors and blood vessel formation," Nature, vol. 407, no. 6801, pp. 242-248, 2000.

[41] M. J. C. Hendrix, E. A. Seftor, P. S. Meltzer et al., "Expression and functional significance of VE-cadherin in aggressive human melanoma cells: role in vasculogenic mimicry," Proceedings of the National Academy of Sciences of the United States of America, vol. 98, no. 14, pp. 8018-8023, 2001.

[42] J. Folkman, "Can mosaic tumor vessels facilitate molecular diagnosis of cancer?" Proceedings of the National Academy of Sciences of the United States of America, vol. 98, no. 2, pp. 398400, 2001.

[43] G. Bergers and L. E. Benjamin, "Tumorigenesis and the angiogenic switch," Nature Reviews Cancer, vol. 3, no. 6, pp. 401-410, 2003.

[44] O. Iliopoulos, A. P. Levy, C. Jiang, W. G. Kaelin, and M. A. Goldberg, "Negative regulation of hypoxia-inducible genes by the von Hippel-Lindau protein," Proceedings of the National Academy of Sciences of the United States of America, vol. 93, no. 20, pp. 10595-10599, 1996.

[45] M. S. Wiesener, P. M. Münchenhagen, I. Berger et al., "Constitutive activation of hypoxia-inducible genes related to overexpression of hypoxia-inducible factor- $1 \alpha$ in clear cell renal carcinomas," Cancer Research, vol. 61, no. 13, pp. 52155222, 2001.

[46] M. M. Baldewijns, I. J. H. Van Vlodrop, P. B. Vermeulen, P. M. M. B. Soetekouw, M. Van Engeland, and A. P. De Bruïne, "VHL and HIF signalling in renal cell carcinogenesis," Journal of Pathology, vol. 221, no. 2, pp. 125-138, 2010.

[47] I. Wacker, M. Sachs, K. Knaup et al., "Key role for activin B in cellular transformation after loss of the von Hippel-Lindau tumor suppressor," Molecular and Cellular Biology, vol. 29, no. 7, pp. 1707-1718, 2009.

[48] J. Pouysségur, F. Dayan, and N. M. Mazure, "Hypoxia signalling in cancer and approaches to enforce tumour regression," Nature, vol. 441, no. 7092, pp. 437-443, 2006.

[49] G. Ghosh, I. V. Subramanian, N. Adhikari et al., "Hypoxiainduced microRNA-424 expression in human endothelial cells regulates HIF- $\alpha$ isoforms and promotes angiogenesis," Journal of Clinical Investigation, vol. 120, no. 11, pp. 41414154, 2010.
[50] J. Loscalzo, "The cellular response to hypoxia: tuning the system with microRNAs," Journal of Clinical Investigation, vol. 120, no. 11, pp. 3815-3817, 2010.

[51] G. L. Semenza, "Targeting HIF-1 for cancer therapy," Nature Reviews Cancer, vol. 3, no. 10, pp. 721-732, 2003.

[52] K. Podar and K. C. Anderson, "A therapeutic role for targeting c-Myc/Hif-1-dependent signaling pathways," Cell Cycle, vol. 9, no. 9, pp. 1722-1728, 2010.

[53] E. R. Fearon and B. Vogelstein, "A genetic model for colorectal tumorigenesis," Cell, vol. 61, no. 5, pp. 759-767, 1990.

[54] A. Moran, P Ortega, C. de Juan et al., "Differential colorectal carcinogenesis: molecular basis and clinical relevance," World Journal of Gastrointestinal Oncology, vol. 2, no. 3, pp. 151$158,2010$.

[55] D. Wang, H. J. S. Huang, A. Kazlauskas, and W. K. Cavenee, "Induction of vascular endothelial growth factor expression in endothelial cells by platelet-derived growth factor through the activation of phosphatidylinositol 3-kinase," Cancer Research, vol. 59, no. 7, pp. 1464-1472, 1999.

[56] G. Tortora, R. Caputo, V. Damiano et al., "Combined blockade of protein kinase A and bcl-2 by antisense strategy induces apoptosis and inhibits tumor growth and angiogenesis," Clinical Cancer Research, vol. 7, no. 8, pp. 2537-2544, 2001.

[57] A. M. Viloria Petit, J. Rak, M. C. Hung et al., "Neutralizing antibodies against epidermal growth factor and ErbB-2/neu receptor tyrosine kinases down-regulate vascular endothelial growth factor production by tumor cells in vitro and in vivo: angiogenic implications for signal transduction therapy of solid tumors," American Journal of Pathology, vol. 151, no. 6, pp. 1523-1530, 1997.

[58] K. F. Chin, J. Greenman, E. Gardiner, H. Kumar, K. Topping, and J. Monson, "Pre-operative serum vascular endothelial growth factor can select patients for adjuvant treatment after curative resection in colorectal cancer," British Journal of Cancer, vol. 83, no. 11, pp. 1425-1431, 2000.

[59] I. Hyodo, T. Doi, H. Endo et al., "Clinical significance of plasma vascular endothelial growth factor in gastrointestinal cancer," European Journal of Cancer, vol. 34, no. 13, pp. 20412045, 1998.

[60] A. Nanashima, M. Ito, I. Sekine et al., "Significance of angiogenic factors in liver metastatic tumors originating from colorectal cancers," Digestive Diseases and Sciences, vol. 43, no. 12, pp. 2634-2640, 1998.

[61] M. M. Taketo, "Cyclooxygenase-2 inhibitors in tumorigenesis (part II)," Journal of the National Cancer Institute, vol. 90, no. 21, pp. 1609-1620, 1998.

[62] L. Milas, K. Kishi, N. Hunter, K. Mason, J. L. Masferrer, and P. J. Tofilon, "Enhancement of tumor response to $\gamma$-radiation by an inhibitor of cyclooxygenase-2 enzyme," Journal of the National Cancer Institute, vol. 91, no. 17, pp. 1501-1504, 1999.

[63] C. E. Eberhart, R. J. Coffey, A. Radhika, F. M. Giardiello, S. Ferrenbach, and R. N. Dubois, "Up-regulation of cyclooxygenase 2 gene expression in human colorectal adenomas and adenocarcinomas," Gastroenterology, vol. 107, no. 4, pp. 1183-1188, 1994.

[64] R. A. Gupta and R. N. DuBois, "Colorectal cancer prevention and treatment by inhibition of cyclooxygenase-2," Nature Reviews Cancer, vol. 1, no. 1, pp. 11-21, 2001.

[65] S. Ogino, G. J. Kirkner, K. Nosho et al., "Cyclooxygenase-2 expression Is an independent predictor of poor prognosis in 
colon cancer," Clinical Cancer Research, vol. 14, no. 24, pp. 8221-8227, 2008.

[66] M. Oshima, J. E. Dinchuk, S. L. Kargman et al., "Suppression of intestinal polyposis in Apc delta716 knockout mice by inhibition of cyclooxygenase 2 (COX-2)," Cell, vol. 87, no. 5, pp. 803-809, 1996.

[67] R. L. Shattuck-Brandt, L. W. Lamps, K. J. Heppner Goss, R. N. DuBois, and L. M. Matrisian, "Differential expression of matrilysin and cyclooxygenase-2 in intestinal and colorectal neoplasms," Molecular Carcinogenesis, vol. 24, no. 3, pp. 177187, 1999.

[68] B. K. Hong, H. M. Kwon, B. K. Lee et al., "Coexpression of cyclooxygenase-2 and matrix metalloproteinases in human aortic atherosclerotic lesions," Yonsei Medical Journal, vol. 41, no. 1 , pp. $82-88,2000$.

[69] W. Dempke, C. Rie, A. Grothey, and H. J. Schmoll, "Cyclooxygenase-2: a novel target for cancer chemotherapy?" Journal of Cancer Research and Clinical Oncology, vol. 127, no. 7, pp. 411-417, 2001.

[70] M. Tsujii, S. Kawano, S. Tsuji, H. Sawaoka, M. Hori, and R. N. DuBois, "Cyclooxygenase regulates angiogenesis induced by colon cancer cells," Cell, vol. 93, no. 5, pp. 705-716, 1998.

[71] M. Majima, M. Isono, Y. Ikeda et al., "Significant roles of inducible cyclooxygenase (COX)-2 in angiogenesis in rat sponge implants," Japanese Journal of Pharmacology, vol. 75, no. 2, pp. 105-114, 1997.

[72] J. L. Masferrer, K. M. Leahy, A. T. Koki et al., "Antiangiogenic and antitumor activities of cyclooxygenase-2 inhibitors," Cancer Research, vol. 60, no. 5, pp. 1306-1311, 2000.

[73] K. Uefuji, T. Ichikura, and H. Mochizuki, "Cyclooxygenase2 expression is related to prostaglandin biosynthesis and angiogenesis in human gastric cancer," Clinical Cancer Research, vol. 6, no. 1, pp. 135-138, 2000.

[74] R. N. DuBois and W. E. Smalley, "Cyclooxygenase, NSAIDs, and colorectal cancer," Journal of Gastroenterology, vol. 31, no. 6, pp. 898-906, 1996.

[75] E. H. Ruder, A. O. Laiyemo, B. I. Graubard, A. R. Hollenbeck, A. Schatzkin, and A. J. Cross, "Non-steroidal antiinflammatory drugs and colorectal cancer risk in a large, prospective cohort," American Journal of Gastroenterology, vol. 106, no. 7, pp. 1340-1350, 2011.

[76] H. M. Arthur, J. Ure, A. J. H. Smith et al., "Endoglin, an ancillary TGF $\beta$ receptor, is required for extraembryonic angiogenesis and plays a key role in heart development," Developmental Biology, vol. 217, no. 1, pp. 42-53, 2000.

[77] C. Li, B. Guo, C. Bernabeu, and S. Kumar, "Angiogenesis in breast cancer: the role of transforming growth factor $\beta$ and CD105," Microscopy Research and Technique, vol. 52, no. 4, pp. 437-449, 2001.

[78] A. A. Romani, A. F. Borghetti, P. Del Rio, M. Sianesi, and P. Soliani, "The risk of developing metastatic disease in colorectal cancer is related to CD105-positive vessel count," Journal of Surgical Oncology, vol. 93, no. 6, pp. 446-455, 2006.

[79] S. Venkatesha, M. Toporsian, C. Lam et al., "Soluble endoglin contributes to the pathogenesis of preeclampsia," Nature Medicine, vol. 12, no. 6, pp. 642-649, 2006.

[80] T. E. Walshe, M. Saint-Geniez, A. S. R. Maharaj, E. Sekiyama, A. E. Maldonado, and P. A. D'Amore, “TGF- $\beta$ is required for vascular barrier function, endothelial survival and homeostasis of the adult microvasculature," PLoS One, vol. 4, no. 4, Article ID e5149, 2009.

[81] B. I. Rini, S. C. Campbell, and B. Escudier, "Renal cell carcinoma," The Lancet, vol. 373, no. 9669, pp. 1119-1132, 2009.
[82] J. S. Lam, J. T. Leppert, A. S. Belldegrun, and R. A. Figlin, "Novel approaches in the therapy of metastatic renal cell carcinoma," World Journal of Urology, vol. 23, no. 3, pp. 202212, 2005.

[83] M. Sun, G. Lughezzani, P. Perrotte, and P. I. Karakiewicz, "Treatment of metastatic renal cell carcinoma," Nature Reviews Urology, vol. 7, no. 6, pp. 327-338, 2010.

[84] A. Takahashi, H. Sasaki, S. J. Kim et al., "Markedly increased amounts of messenger RNAs for vascular endothelial growth factor and placenta growth factor in renal cell carcinoma associated with angiogenesis," Cancer Research, vol. 54, no. 15, pp. 4233-4237, 1994.

[85] H. T. Cohen and F. J. McGovern, "Renal-cell carcinoma," The New England Journal of Medicine, vol. 353, no. 23, pp. 24772490, 2005.

[86] O. Iliopoulos, A. Kibel, S. Gray, and W. G. Kaelin, "Tumour suppression by the human von Hippel-Lindau gene product," Nature Medicine, vol. 1, no. 8, pp. 822-826, 1995.

[87] F. Chen, T. Kishida, F. M. Duh et al., "Suppression of growth of renal carcinoma cells by the von Hippel-Lindau tumor suppressor gene," Cancer Research, vol. 55, no. 21, pp. 48044807, 1995.

[88] M. Zimmer, D. Doucette, N. Siddiqui, and O. Iliopoulos, "Inhibition of hypoxia-inducible factor is sufficient for growth suppression of VHL-/- tumors," Molecular Cancer Research, vol. 2, no. 2, pp. 89-95, 2004.

[89] L. Gossage and T. Eisen, "Alterations in VHL as potential biomarkers in renal-cell carcinoma," Nature Reviews Clinical Oncology, vol. 7, no. 5, pp. 277-288, 2010.

[90] M. Ohh, R. L. Yauch, K. M. Lonergan et al., "The von HippelLindau tumor suppressor protein is required for proper assembly of an extracellular fibronectin matrix," Molecular Cell, vol. 1, no. 7, pp. 959-968, 1998.

[91] G. Kurban, E. Duplan, N. Ramlal et al., "Collagen matrix assembly is driven by the interaction of von Hippel-Lindau tumor suppressor protein with hydroxylated collagen IV alpha 2," Oncogene, vol. 27, no. 7, pp. 1004-1012, 2008.

[92] V. A. Carroll and M. Ashcroft, "Regulation of angiogenic factors by HDM2 in renal cell carcinoma," Cancer Research, vol. 68, no. 2, pp. 545-552, 2008.

[93] R. H. Thompson, S. M. Kuntz, B. C. Leibovich et al., "Tumor B7-H1 is associated with poor prognosis in renal cell carcinoma patients with long-term follow-up," Cancer Research, vol. 66, no. 7, pp. 3381-3385, 2006.

[94] B. F. Johnson, T. M. Clay, A. C. Hobeika, H. K. Lyerly, and M. A. Morse, "Vascular endothelial growth factor and immunosuppression in cancer: current knowledge and potential for new therapy," Expert Opinion on Biological Therapy, vol. 7, no. 4, pp. 449-460, 2007.

[95] S. Biswas and T. Eisen, "Immunotherapeutic strategies in kidney cancer-when TKIs are not enough," Nature Reviews Clinical Oncology, vol. 6, no. 8, pp. 478-487, 2009.

[96] American Cancer Society, "Cancer Facts \& Figures 2010," 2010, http://www.cancer.org/acs/groups/content/@epidemiologysurveilance/documents/document/acspc-026238.pdf.

[97] A. L. Harris, S. Fox, R. Bicknell et al., "Gene therapy through signal transduction pathways and angiogenic growth factors as therapeutic targets in breast cancer," Cancer, vol. 74, no. 3, pp. 1021-1025, 1994.

[98] J. Rak, Y. Mitsuhashi, C. Sheehan et al., "Oncogenes and tumor angiogenesis: differential modes of vascular endothelial growth factor up-regulation in ras-transformed epithelial 
cells and fibroblasts," Cancer Research, vol. 60, no. 2, pp. 490498, 2000.

[99] L. F. Brown, A. J. Guidi, S. J. Schnitt et al., "Vascular stroma formation in carcinoma in situ, invasive carcinoma, and metastatic carcinoma of the breast," Clinical Cancer Research, vol. 5, no. 5, pp. 1041-1056, 1999.

[100] K. S. Kimbro and J. W. Simons, "Hypoxia-inducible factor1 in human breast and prostate cancer," Endocrine-Related Cancer, vol. 13, no. 3, pp. 739-749, 2006.

[101] A. Scorilas, A. Karameris, N. Arnogiannaki et al., "Overexpression of matrix-metalloproteinase-9 in human breast cancer: a potential favourable indicator in node-negative patients," British Journal of Cancer, vol. 84, no. 11, pp. 14881496, 2001.

[102] G. Bergers, R. Brekken, G. McMahon et al., "Matrix metalloproteinase-9 triggers the angiogenic switch during carcinogenesis," Nature Cell Biology, vol. 2, no. 10, pp. 737744, 2000.

[103] R. R. Greb, I. Maier, D. Wallwiener, and L. Kiesel, "Vascular endothelial growth factor A (VEGF-A) mRNA expression levels decrease after menopause in normal breast tissue but not in breast cancer lesions," British Journal of Cancer, vol. 81, no. 2, pp. 225-231, 1999.

[104] M. D. Mueller, J. L. Vigne, A. Minchenko, D. I. Lebovic, D. C. Leitman, and R. N. Taylor, "Regulation of vascular endothelial growth factor (VEGF) gene transcription by estrogen receptors $\alpha$ and $\beta$," Proceedings of the National Academy of Sciences of the United States of America, vol. 97, no. 20, pp. 10972-10977, 2000.

[105] H. Buteau-Lozano, M. Ancelin, B. Lardeux, J. Milanini, and M. Perrot-Applanat, "Transcriptional regulation of vascular endothelial growth factor by estradiol and tamoxifen in breast cancer cells: a complex interplay between estrogen receptors $\alpha$ and $\beta$," Cancer Research, vol. 62, no. 17, pp. 49774984, 2002.

[106] D. J. Slamon, G. M. Clark, and S. G. Wong, "Human breast cancer: correlation of relapse and survival with amplification of the HER-2/neu oncogene," Science, vol. 235, no. 4785, pp. 177-182, 1987.

[107] M. J. Piccart-Gebhart, M. Procter, B. Leyland-Jones et al., "Trastuzumab after adjuvant chemotherapy in HER2positive breast cancer," The New England Journal of Medicine, vol. 353, no. 16, pp. 1659-1672, 2005.

[108] X. F. Wen, G. Yang, W. Mao et al., "HER2 signaling modulates the equilibrium between pro- and antiangiogenic factors via distinct pathways: implications for HER2-targeted antibody therapy," Oncogene, vol. 25, no. 52, pp. 6986-6996, 2006.

[109] K. S. Klos, S. L. Wyszomierski, M. Sun et al., "ErbB2 increases vascular endothelial growth factor protein synthesis via activation of mammalian target of rapamycin/p70S6K leading to increased angiogenesis and spontaneous metastasis of human breast cancer cells," Cancer Research, vol. 66, no. 4, pp. 2028-2037, 2006.

[110] P. E. Reid, N. J. Brown, and I. Holen, "Breast cancer cells stimulate osteoprotegerin (OPG) production by endothelial cells through direct cell contact," Molecular Cancer, vol. 8, p. 49, 2009.

[111] S. S. Cross, Z. Yang, N. J. Brown et al., "Osteoprotegerin (OPG) - a potential new role in the regulation of endothelial cell phenotype and tumour angiogenesis?" International Journal of Cancer, vol. 118, no. 8, pp. 1901-1908, 2006.

[112] T. Hayashida, F. Takahashi, N. Chiba et al., "HOXB9, a gene overexpressed in breast cancer, promotes tumorigenicity and lung metastasis," Proceedings of the National Academy of
Sciences of the United States of America, vol. 107, no. 3, pp. 1100-1105, 2010.

[113] P. Greer, "Closing in on the biological functions of Fps/Fes and Fer," Nature Reviews Molecular Cell Biology, vol. 3, no. 4, pp. 278-289, 2002.

[114] S. Zhang, V. Chitu, E. R. Stanley, B. E. Elliott, and P. A. Greer, "Fes tyrosine kinase expression in the tumor niche correlates with enhanced tumor growth, angiogenesis, circulating tumor cells, metastasis, and infiltrating macrophages," Cancer Research, vol. 71, no. 4, pp. 1465-1473, 2011.

[115] S. Garvin and C. Dabrosin, "Tamoxifen inhibits secretion of vascular endothelial growth factor in breast cancer in vivo," Cancer Research, vol. 63, no. 24, pp. 8742-8748, 2003.

[116] U. W. Nilsson, J. A. Jönsson, and C. Dabrosin, "Tamoxifen decreases extracellular TGF- $\beta 1$ secreted from breast cancer cells-a post-translational regulation involving matrix metalloproteinase activity," Experimental Cell Research, vol. 315, no. 1, pp. 1-9, 2009.

[117] G. Lindahl, N. Saarinen, A. Abrahamsson, and C. Dabrosin, "Tamoxifen, flaxseed, and the lignan enterolactone increase stroma- and cancer cell-derived IL-1Ra and decrease tumor angiogenesis in estrogen-dependent breast cancer," Cancer Research, vol. 71, no. 1, pp. 51-60, 2011.

[118] B. Sirohi and R. Powles, "Multiple myeloma," The Lancet, vol. 363, no. 9412, pp. 875-887, 2004.

[119] M. S. Raab, K. Podar, I. Breitkreutz, P. G. Richardson, and K. C. Anderson, "Multiple myeloma," The Lancet, vol. 374, no. 9686, pp. 324-339, 2009.

[120] D. Ribatti and A. Vacca, "The role of microenvironment in tumor angiogenesis," Genes and Nutrition, vol. 3, no. 1, pp. 29-34, 2008.

[121] A. Vacca and D. Ribatti, "Bone marrow angiogenesis in multiple myeloma," Leukemia, vol. 20, no. 2, pp. 193-199, 2006.

[122] D. Ribatti, B. Nico, and A. Vacca, "Importance of the bone marrow microenvironment in inducing the angiogenic response in multiple myeloma," Oncogene, vol. 25, no. 31, pp. 4257-4266, 2006.

[123] K. Podar and K. C. Anderson, "The pathophysiologic role of VEGF in hematologic malignancies: therapeutic implications," Blood, vol. 105, no. 4, pp. 1383-1395, 2005.

[124] T. Hideshima, C. Mitsiades, G. Tonon, P. G. Richardson, and K. C. Anderson, "Understanding multiple myeloma pathogenesis in the bone marrow to identify new therapeutic targets," Nature Reviews Cancer, vol. 7, no. 8, pp. 585-598, 2007.

[125] K. Podar, T. Hideshima, D. Chauhan, and K. C. Anderson, "Targeting signalling pathways for the treatment of multiple myeloma," Expert Opinion on Therapeutic Targets, vol. 9, no. 2, pp. 359-381, 2005.

[126] C. Jakob, J. Sterz, I. Zavrski et al., "Angiogenesis in multiple myeloma," European Journal of Cancer, vol. 42, no. 11, pp. 1581-1590, 2006.

[127] K. Podar and K. C. Anderson, "Inhibition of VEGF signaling pathways in multiple myeloma and other malignancies," Cell Cycle, vol. 6, no. 5, pp. 538-542, 2007.

[128] A. Vacca, R. Ria, F. Semeraro et al., "Endothelial cells in the bone marrow of patients with multiple myeloma," Blood, vol. 102, no. 9, pp. 3340-3348, 2003.

[129] A. Pellegrino, F. Antonaci, F. Russo et al., "CXCR3-binding chemokines in multiple myeloma," Cancer Letters, vol. 207, no. 2, pp. 221-227, 2004. 
[130] B. Heissig, Y. Ohki, Y. Sato, S. Rafii, Z. Werb, and K. Hattori, "A role for niches in hematopoietic cell development," Hematology, vol. 10, no. 3, pp. 247-253, 2005.

[131] H. G. Kopp, S. T. Avecilla, A. T. Hooper, and S. Rafii, “The bone marrow vascular niche: home of HSC differentiation and mobilization," Physiology, vol. 20, no. 5, pp. 349-356, 2005.

[132] J. Folkman, "Angiogenesis: an organizing principle for drug discovery?” Nature Reviews Drug Discovery, vol. 6, no. 4, pp. 273-286, 2007.

[133] R. J. D’Amato, M. S. Loughnan, E. Flynn, and J. Folkman, "Thalidomide is an inhibitor of angiogenesis," Proceedings of the National Academy of Sciences of the United States of America, vol. 91, no. 9, pp. 4082-4085, 1994.

[134] S. Singhal, J. Mehta, R. Desikan et al., "Antitumor activity of thalidomide in refractory multiple myeloma," The New England Journal of Medicine, vol. 341, no. 21, pp. 1565-1571, 1999.

[135] J. B. Bartlett, K. Dredge, and A. G. Dalgleish, "The evolution of thalidomide and its IMiD derivatives as anticancer agents," Nature Reviews Cancer, vol. 4, no. 4, pp. 314-322, 2004.

[136] P. G. Richardson, R. L. Schlossman, E. Weller et al., "Immunomodulatory drug CC-5013 overcomes drug resistance and is well tolerated in patients with relapsed multiple myeloma," Blood, vol. 100, no. 9, pp. 3063-3067, 2002.

[137] R. J. D’Amato, S. Lentzsch, K. C. Anderson, and M. S. Rogers, "Mechanism of action of thalidomide and 3aminothalidomide in multiple myeloma," Seminars in Oncology, vol. 28, no. 6, pp. 597-601, 2001.

[138] T. Hideshima, D. Chauhan, Y. Shima et al., "Thalidomide and its analogs overcome drug resistance of human multiple myeloma cells to conventional therapy," Blood, vol. 96, no. 9, pp. 2943-2950, 2000.

[139] Genentech, "Avastin (bevacizumab) product insert," 2011, http://www.gene.com/gene/products/information/pdf/ avastin-prescribing.pdf

[140] G. Folprecht and C. H. Köhne, "The role of new agents in the treatment of colorectal cancer," Oncology, vol. 66, no. 1, pp. $1-17,2004$.

[141] L. G. Presta, H. Chen, S. J. O’Connor et al., "Humanization of an anti-vascular endothelial growth factor monoclonal antibody for the therapy of solid tumors and other disorders," Cancer Research, vol. 57, no. 20, pp. 4593-4599, 1997.

[142] M. L. Salgaller, "Technology evaluation: bevacizumab, Genentech/Roche," Current Opinion in Molecular Therapeutics, vol. 5, no. 6, pp. 657-667, 2003.

[143] V. C. E. De Gramont and J. Tabernero, "AVANT: results from a randomized, three-arm multinational phase III study to investigate bevacizumab with either XELOX or FOLFOX4 versus FOLFOX4 alone as adjuvant treatment for colon cancer," in Proceedings of the Gastrointestinal Cancer Symposium (ASCO), vol. 29, abstract no 362, 2011.

[144] C. J. Allegra, G. Yothers, M. J. O’Connell et al., "Initial safety report of NSABP C-08: a randomized phase III study of modified FOLFOX6 with or without bevacizumab for the adjuvant treatment of patients with stage II or III colon cancer," Journal of Clinical Oncology, vol. 27, no. 20, pp. 33853390, 2009.

[145] G. A. Poultsides, E. L. Servais, L. B. Saltz et al., "Outcome of primary tumor in patients with synchronous stage IV colorectal cancer receiving combination chemotherapy without surgery as initial treatment," Journal of Clinical Oncology, vol. 27, no. 20, pp. 3379-3384, 2009.
[146] N. Ferrara, K. J. Hillan, H. P. Gerber, and W. Novotny, "Discovery and development of bevacizumab, an anti-VEGF antibody for treating cancer," Nature Reviews Drug Discovery, vol. 3, no. 5, pp. 391-400, 2004.

[147] B. Escudier, A. Pluzanska, P. Koralewski et al., "Bevacizumab plus interferon alfa-2a for treatment of metastatic renal cell carcinoma: a randomised, double-blind phase III trial," The Lancet, vol. 370, no. 9605, pp. 2103-2111, 2007.

[148] B. I. Rini, S. Halabi, J. E. Rosenberg et al., "Bevacizumab plus interferon alfa compared with interferon alfa monotherapy in patients with metastatic renal cell carcinoma: CALGB 90206," Journal of Clinical Oncology, vol. 26, no. 33, pp. 54225428, 2008.

[149] B. Escudier, J. Bellmunt, S. Négrier et al., "Phase III trial of bevacizumab plus interferon alfa- $2 a$ in patients with metastatic renal cell carcinoma (AVOREN): final analysis of overall survival," Journal of Clinical Oncology, vol. 28, no. 13, pp. 2144-2150, 2010.

[150] B. I. Rini, S. Halabi, J. E. Rosenberg et al., "Phase III trial of bevacizumab plus interferon alfa versus interferon alfa monotherapy in patients with metastatic renal cell carcinoma: final results of CALGB 90206," Journal of Clinical Oncology, vol. 28, no. 13, pp. 2137-2143, 2010.

[151] R. Gray, S. Bhattacharya, C. Bowden, K. Miller, and R. L. Comis, "Independent review of E2100: a phase III trial of bevacizumab plus paclitaxel versus paclitaxel in women with metastatic breast cancer," Journal of Clinical Oncology, vol. 27, no. 30, pp. 4966-4972, 2009.

[152] T. Fojo and J. Wilkerson, "Bevacizumab and breast cancer: the E2100 outlier," The Lancet Oncology, vol. 11, no. 12, pp. 1117-1119, 2010.

[153] B. Klencke, S. Bhattacharya, M. K. Samant et al., "Independet review of E2100 progression-free survival (PFS) with the addition of bevacizumab (B) to paclitaxel (P) as initial chemotherpary for metastatic brease cancer (MBC)," in Proceedings of the 2008 ASCO Annual Meeting, vol. 26, abstract 1036, Poster Discussion Session, Breast CancerMetastatic, 2008.

[154] D. W. Miles, A. Chan, L. Y. Dirix et al., "Phase III study of bevacizumab plus docetaxel compared with placebo plus docetaxel for the first-line treatment of human epidermal growth factor receptor 2-negative metastatic breast cancer," Journal of Clinical Oncology, vol. 28, no. 20, pp. 3239-3247, 2010.

[155] N. J. Robert, V. Diéras, J. Glaspy et al., "RIBBON-1: randomized, double-blind, placebo-controlled, phase III trial of chemotherapy with or without bevacizumab for firstline treatment of human epidermal growth factor receptor 2-negative, locally recurrent or metastatic breast cancer," Journal of Clinical Oncology, vol. 29, no. 10, pp. 1252-1260, 2011.

[156] H. J. Burstein, "Bevacizumab for advanced breast cancer: all tied up with a RIBBON?" Journal of Clinical Oncology, vol. 29, no. 10, pp. 1232-1235, 2011.

[157] D. F. Hayes, "Bevacizumab treatment for solid tumors: boon or bust?" Journal of the American Medical Association, vol. 305, no. 5, pp. 506-508, 2011.

[158] V. Ranpura, S. Hapan, and S. Wu, "Treatment-related mortality with bevacizumab in cancer patients: a metaanalysis," Journal of the American Medical Association, vol. 305, no. 5, pp. 487-494, 2011.

[159] R. S. Herbst and W. K. Hong, "IMC-C225, an anti-epidermal growth factor receptor monoclonal antibody for treatment of 
head and neck cancer," Seminars in Oncology, vol. 29, no. 5, supplement 14, pp. 18-30, 2002.

[160] R. S. Herbst, E. S. Kim, and P. M. Harari, "IMC-C225, an anti-epidermal growth factor receptor monoclonal antibody, for treatment of head and neck cancer," Expert Opinion on Biological Therapy, vol. 1, no. 4, pp. 719-732, 2001.

[161] E. S. Kim, F. R. Khuri, and R. S. Herbst, "Epidermal growth factor receptor biology (IMC-C225)," Current Opinion in Oncology, vol. 13, no. 6, pp. 506-513, 2001.

[162] G. M. Sclabas, S. Fujioka, C. Schmidt, Z. Fan, D. B. Evans, and P. J. Chiao, "Restoring apoptosis in pancreatic cancer cells by targeting the nuclear factor-kappaB signaling pathway with the anti-epidermal growth factor antibody IMC-C225," Journal of Gastrointestinal Surgery, vol. 7, no. 1, pp. 37-43, 2003.

[163] Z. Wainberg and J. R. Hecht, "Panitumumab in colon cancer: a review and summary of ongoing trials," Expert Opinion on Biological Therapy, vol. 6, no. 11, pp. 1229-1235, 2006.

[164] M. W. Saif and M. Cohenuram, "Role of panitumumab in the management of metastatic colorectal cancer of metastatic colorectal cancer," Clinical Colorectal Cancer, vol. 6, no. 2, pp. 118-124, 2006.

[165] T. B. Gibson, A. Ranganathan, and A. Grothey, "Randomized phase III trial results of Panitumumab, a fully human antiepidermal growth factor receptor monoclonal antibody, in metastatic colorectal cancer," Clinical Colorectal Cancer, vol. 6, no. 1, pp. 29-31, 2006.

[166] P. Tyagi, E. Chu, and V. K. Jain, "Recent results and ongoing trials with panitumumab (ABX-EGF), a fully human antiepidermal growth factor receptor antibody, in metastatic colorectal cancer," Clinical Colorectal Cancer, vol. 5, no. 1, pp. 21-23, 2005.

[167] J. Holash, S. Davis, N. Papadopoulos et al., "VEGF-Trap: a VEGF blocker with potent antitumor effects," Proceedings of the National Academy of Sciences of the United States of America, vol. 99, no. 17, pp. 11393-11398, 2002.

[168] Q. S. C. Chu, "Aflibercept (AVE0005): an alternative strategy for inhibiting tumour angiogenesis by vascular endothelial growth factors," Expert Opinion on Biological Therapy, vol. 9, no. 2, pp. 263-271, 2009.

[169] E. S. Kim, A. Serur, J. Huang et al., "Potent VEGF blockade causes regression of coopted vessels in a model of neuroblastoma," Proceedings of the National Academy of Sciences of the United States of America, vol. 99, no. 17, pp. 11399-11404, 2002.

[170] G. C. Jayson, J. Zweit, A. Jackson et al., "Molecular imaging and biological evaluation of HuMV833 anti-VEGF antibody: implications for trial design of antiangiogenic antibodies," Journal of the National Cancer Institute, vol. 94, no. 19, pp. 1484-1493, 2002.

[171] G. C. Jayson, C. Mulatero, M. Ranson et al., "Phase I investigation of recombinant anti-human vascular endothelial growth factor antibody in patients with advanced cancer," European Journal of Cancer, vol. 41, no. 4, pp. 555-563, 2005.

[172] Y. Wu, Z. Zhong, J. Huber et al., "Anti-vascular endothelial growth factor receptor- 1 antagonist antibody as a therapeutic agent for cancer," Clinical Cancer Research, vol. 12, no. 21, pp. 6573-6584, 2006.

[173] Y. Krupitskaya and H. A. Wakelee, "Ramucirumab, a fully human $\mathrm{mAb}$ to the transmembrane signaling tyrosine kinase VEGFR-2 for the potential treatment of cancer," Current Opinion in Investigational Drugs, vol. 10, no. 6, pp. 597-605, 2009.
[174] J. MacKey, K. Gelmon, M. Martin et al., "TRIO-012: a multicenter, multinational, randomized, double-blind phase III study of IMC-1121B plus docetaxel versus placebo plus docetaxel in previously untreated patients with HER2negative, unresectable, locally recurrent or metastatic breast cancer," Clinical Breast Cancer, vol. 9, no. 4, pp. 258-261, 2009.

[175] C. A. Hudis, "Trastuzumab-mechanism of action and use in clinical practice," The New England Journal of Medicine, vol. 357, no. 1, pp. 39-51, 2007.

[176] O. Casanovas, D. J. Hicklin, G. Bergers, and D. Hanahan, "Drug resistance by evasion of antiangiogenic targeting of VEGF signaling in late-stage pancreatic islet tumors," Cancer Cell, vol. 8, no. 4, pp. 299-309, 2005.

[177] S. P. Ivy, J. Y. Wick, and B. M. Kaufman, "An overview of small-molecule inhibitors of VEGFR signaling," Nature Reviews Clinical Oncology, vol. 6, no. 10, pp. 569-579, 2009.

[178] K. Imai and A. Takaoka, "Comparing antibody and smallmolecule therapies for cancer," Nature Reviews Cancer, vol. 6, no. 9, pp. 714-727, 2006.

[179] T. B. Lowinger, B. Riedl, J. Dumas, and R. A. Smith, "Design and discovery of small molecules targeting raf-1 kinase," Current Pharmaceutical Design, vol. 8, no. 25, pp. 2269-2278, 2002.

[180] H. Richly, P. Kupsch, K. Passage et al., "A phase I clinical and pharmacokinetic study of the Raf kinase inhibitor (RKI) BAY 43-9006 administered in combination with doxorubicin in patients with solid tumors," International Journal of Clinical Pharmacology and Therapeutics, vol. 41, no. 12, pp. 620-621, 2003.

[181] S. Faivre, G. Demetri, W. Sargent, and E. Raymond, "Molecular basis for sunitinib efficacy and future clinical development," Nature Reviews Drug Discovery, vol. 6, no. 9, pp. 734-745, 2007.

[182] D. B. Mendel, A. Douglas Laird, X. Xin et al., "In vivo antitumor activity of SU11248, a novel tyrosine kinase inhibitor targeting vascular endothelial growth factor and platelet-derived growth factor receptors: determination of a pharmacokinetic/pharmacodynamic relationship," Clinical Cancer Research, vol. 9, no. 1 I, pp. 327-337, 2003.

[183] A. J. Schueneman, E. Himmelfarb, L. Geng et al., "SU11248 maintenance therapy prevents tumor regrowth after fractionated irradiation of murine tumor models," Cancer Research, vol. 63, no. 14, pp. 4009-4016, 2003.

[184] A. M. O'Farrell, T. J. Abrams, H. A. Yuen et al., "SU11248 is a novel FLT3 tyrosine kinase inhibitor with potent activity in vitro and in vivo," Blood, vol. 101, no. 9, pp. 3597-3605, 2003.

[185] R. J. Motzer, T. E. Hutson, P. Tomczak et al., "Sunitinib versus interferon alfa in metastatic renal-cell carcinoma," The New England Journal of Medicine, vol. 356, no. 2, pp. 115-124, 2007.

[186] R. J. Motzer, N. Agarwal, C. Beard et al., "NCCN clinical practice guidelines in oncology: kidney cancer," Journal of the National Comprehensive Cancer Network, vol. 7, no. 6, pp. 618-630, 2009.

[187] S. George, P. Merriam, R. G. Maki et al., "Multicenter phase II trial of sunitinib in the treatment of nongastrointestinal stromal tumor sarcomas," Journal of Clinical Oncology, vol. 27, no. 19, pp. 3154-3160, 2009.

[188] R. T. Abraham and J. J. Gibbons, "The mammalian target of rapamycin signaling pathway: twists and turns in the road to cancer therapy," Clinical Cancer Research, vol. 13, no. 11, pp. 3109-3114, 2007. 
[189] D. M. Sabatini, "mTOR and cancer: insights into a complex relationship," Nature Reviews Cancer, vol. 6, no. 9, pp. 729734, 2006.

[190] G. Hudes, M. Carducci, P. Tomczak et al., "Temsirolimus, interferon alfa, or both for advanced renal-cell carcinoma," The New England Journal of Medicine, vol. 356, no. 22, pp. 2271-2281, 2007.

[191] R. J. Motzer, B. Escudier, S. Oudard et al., "Efficacy of everolimus in advanced renal cell carcinoma: a double-blind, randomised, placebo-controlled phase III trial," The Lancet, vol. 372, no. 9637, pp. 449-456, 2008.

[192] S. S. Agarwala and S. Case, "Everolimus (RAD001) in the treatment of advanced renal cell carcinoma: a review," Oncologist, vol. 15, no. 3, pp. 236-245, 2010.

[193] C. N. Sternberg, I. D. Davis, J. Mardiak et al., "Pazopanib in locally advanced or metastatic renal cell carcinoma: results of a randomized phase III trial," Journal of Clinical Oncology, vol. 28, no. 6, pp. 1061-1068, 2010.

[194] K. Podar, G. Tonon, M. Sattler et al., "The small-molecule VEGF receptor inhibitor pazopanib (GW786034B) targets both tumor and endothelial cells in multiple myeloma," Proceedings of the National Academy of Sciences of the United States of America, vol. 103, no. 51, pp. 19478-19483, 2006.

[195] H. S. Rugo, R. S. Herbst, G. Liu et al., "Phase I trial of the oral antiangiogenesis agent AG-013736 in patients with advanced solid tumors: pharmacokinetic and clinical results," Journal of Clinical Oncology, vol. 23, no. 24, pp. 5474-5483, 2005.

[196] B. I. Rini, G. Wilding, G. Hudes et al., "Phase II study of axitinib in sorafenib-refractory metastatic renal cell carcinoma," Journal of Clinical Oncology, vol. 27, no. 27, pp. 4462-4468, 2009.

[197] J. H. Schiller, T. Larson, S. H. I. Ou et al., "Efficacy and safety of axitinib in patients with advanced non-small-cell lung cancer: results from a phase II study," Journal of Clinical Oncology, vol. 27, no. 23, pp. 3836-3841, 2009.

[198] J. P. Spano, C. Chodkiewicz, J. Maurel et al., "Efficacy of gemcitabine plus axitinib compared with gemcitabine alone in patients with advanced pancreatic cancer: an open-label randomised phase II study," The Lancet, vol. 371, no. 9630, pp. 2101-2108, 2008.

[199] J. C. Bendell, C. Tournigand, T.C. Bednarczyk et al., "Axitinib or bevacizumab plus FOLFOX or FOLFIRI as second-line therapy in patients with colorectal cancer," in Proceedings of the Gastrointestinal Cancer Symposium (ASCO), vol. 29, abstract 478, 2011.

[200] Y. Ito, N. Tokudome, T. Sugihara, S. Takahashi, and K. Hatake, "Does lapatinib, a small-molecule tyrosine kinase inhibitor, constitute a breakthrough in the treatment of breast cancer?" Breast Cancer, vol. 14, no. 2, pp. 156-162, 2007.

[201] B. Moy and P. E. Goss, "Lapatinib: current status and future directions in breast cancer," Oncologist, vol. 11, no. 10, pp. 1047-1057, 2006.

[202] H. A. Burris, "Dual kinase inhibition in the treatment of breast cancer: initial experience with the EGFR/ErbB-2 inhibitor lapatinib," Oncologist, supplement 3, no. 3, pp. 1015, 2004.

[203] F. Montemurro, G. Valabrega, and M. Aglietta, "Lapatinib: a dual inhibitor of EGFR and HER2 tyrosine kinase activity," Expert Opinion on Biological Therapy, vol. 7, no. 2, pp. 257268, 2007.

[204] C. E. Geyer, J. Forster, D. Lindquist et al., "Lapatinib plus capecitabine for HER2-positive advanced breast cancer," The
New England Journal of Medicine, vol. 355, no. 26, pp. 27332743, 2006.

[205] G. E. Konecny, M. D. Pegram, N. Venkatesan et al., "Activity of the dual kinase inhibitor lapatinib (GW572016) against HER-2-overexpressing and trastuzumab-treated breast cancer cells," Cancer Research, vol. 66, no. 3, pp. 1630-1639, 2006.

[206] I. Chu, K. Blackwell, S. Chen, and J. Slingerland, "The dual ErbB1/ErbB2 inhibitor, lapatinib (GW572016), cooperates with tamoxifen to inhibit both cell proliferationand estrogen-dependent gene expression in antiestrogenresistant breast cancer," Cancer Research, vol. 65, no. 1, pp. 18-25, 2005.

[207] R. S. Kerbel, "Antiangiogenic therapy: a universal chemosensitization strategy for cancer?" Science, vol. 312, no. 5777, pp. 1171-1175, 2006.

[208] R. S. Kerbel and B. A. Kamen, "The anti-angiogenic basis of metronomic chemotherapy," Nature Reviews Cancer, vol. 4, no. 6, pp. 423-436, 2004. 


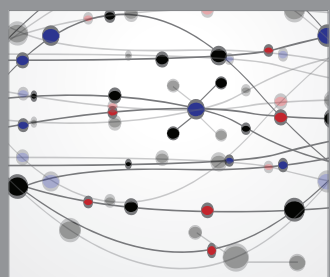

The Scientific World Journal
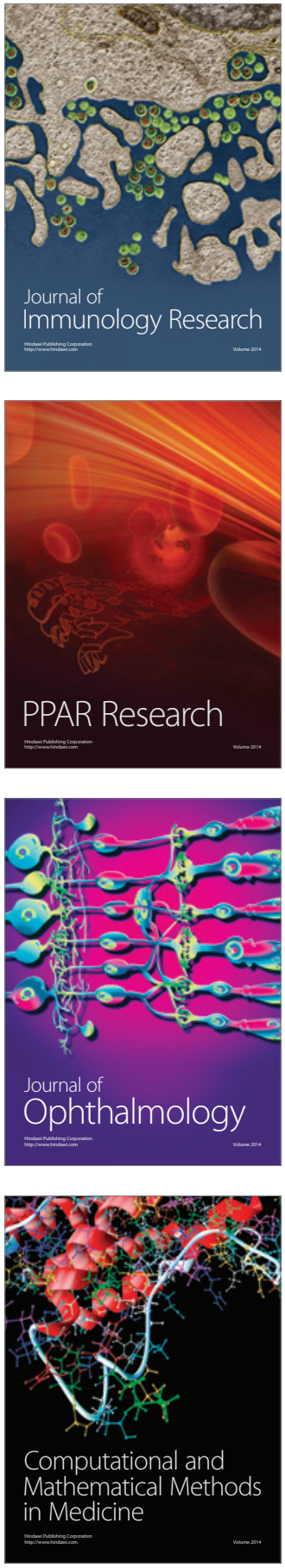

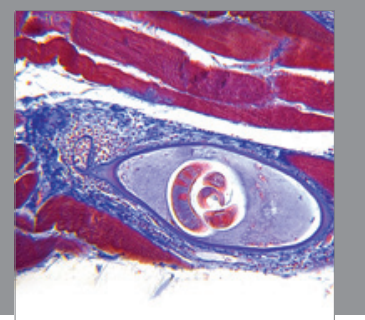

Gastroenterology

Research and Practice
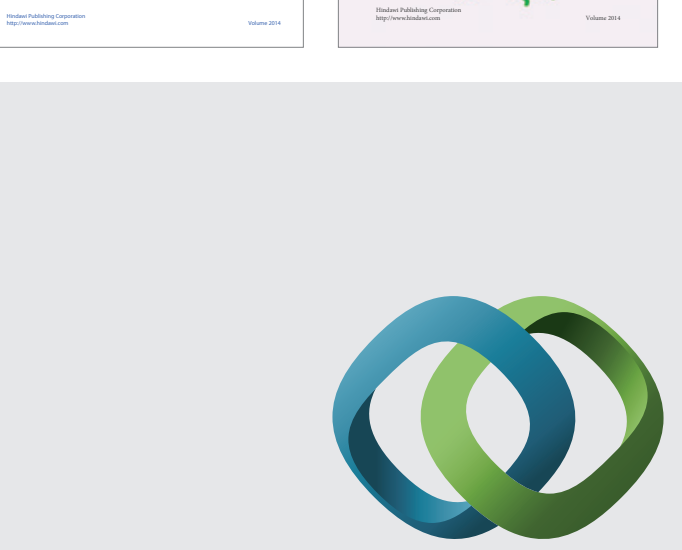

\section{Hindawi}

Submit your manuscripts at

http://www.hindawi.com
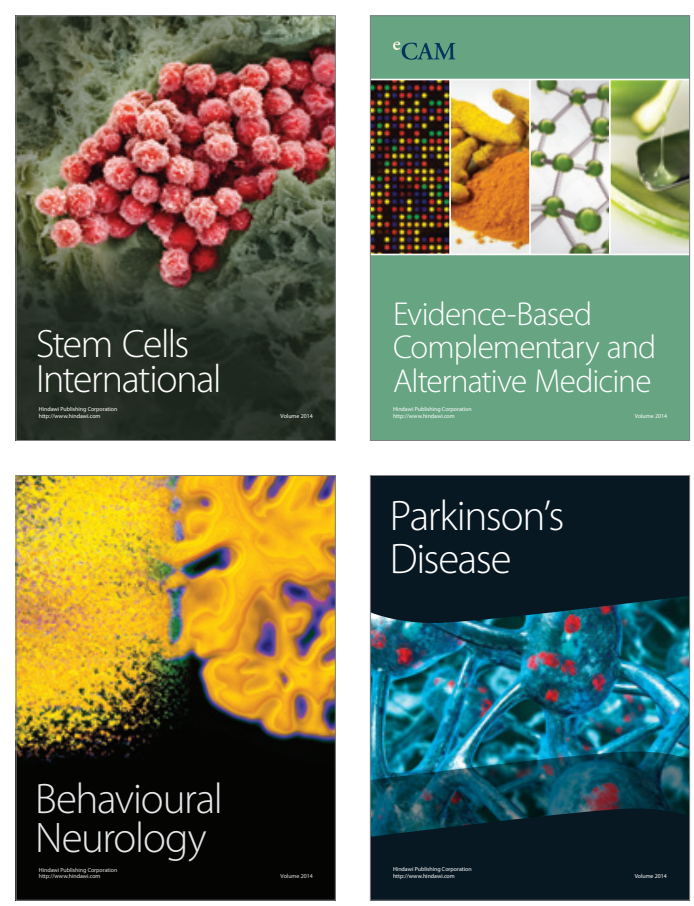

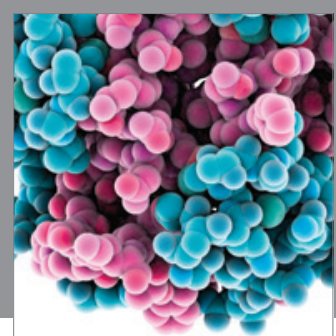

Journal of
Diabetes Research

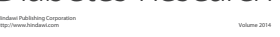

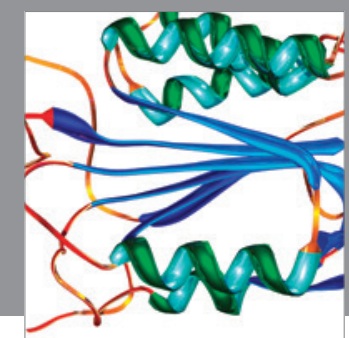

Disease Markers
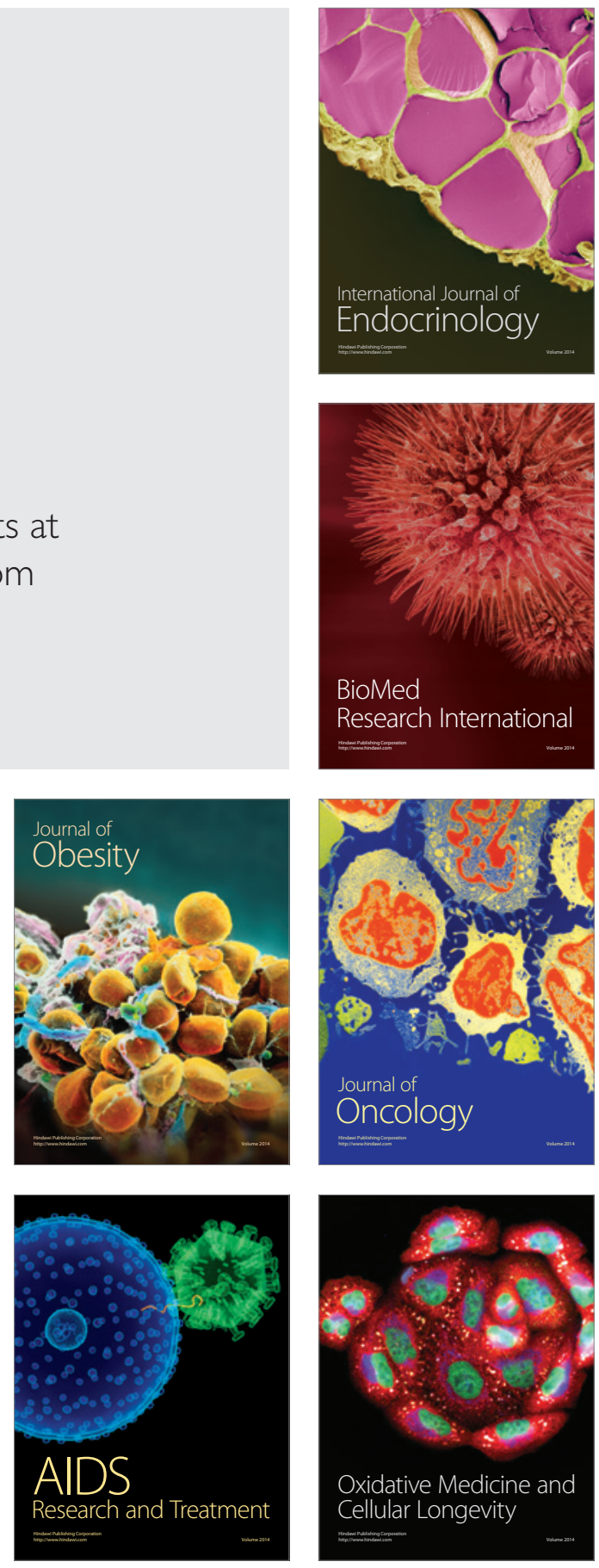